Aus der Poliklinik für Präventive Zahnmedizin, Parodontologie und Kariologie (Prof. Dr. med. dent. A. Wiegand) im Zentrum Zahn-, Mund- und Kieferheilkunde der Medizinischen Fakultät der Universität Göttingen

\title{
Einfluss geschlechtsspezifischer Unterschiede des Speichels auf die Entwicklung dentaler Erosionen: eine In-situ-Studie
}

\author{
INAUGURAL-DISSERTATION \\ zur Erlangung des Doktorgrades \\ (für Zahnmedizin) \\ der Medizinischen Fakultät der \\ Georg-August-Universität zu Göttingen \\ vorgelegt von \\ Anne Pauline Rosemann (geb. Burgdorf) \\ aus \\ Hildesheim
}

Göttingen 2021 
Dekan:

Prof. Dr. med. W. Brück

\section{Betreuungsausschuss}

Betreuerin:

Prof. Dr. med. dent. A. Wiegand

Ko-Betreuer:

Prof. Dr. med. D. Doenecke

\section{Prüfungskommission}

Referentin:

Prof. Dr. med. dent. A. Wiegand

Ko-Referent:

Prof. Dr. med. D. Doenecke

Drittreferent/in:

Prof. Dr. med. R. Dressel

Datum der mündlichen Prüfung: 09.11.2021 
Hiermit erkläre ich, die Dissertation mit dem Titel "Einfluss geschlechtsspezifischer Unterschiede des Speichels auf die Entwicklung dentaler Erosionen: eine In-situ-Studie" eigenständig angefertigt und keine anderen als die von mir angegebenen Quellen und Hilfsmittel verwendet zu haben.

Göttingen, den 11.05.2021

(Unterschrift) 
Die Daten, auf denen die vorliegende Arbeit basiert, wurden publiziert:

Wiegand A, Rosemann A, Hoch M, Barke S, Dakna M, Kanzow P (2019): Erosion-protective capacity of the salivary pellicle of female and male subjects is not different. Caries Res $\underline{53}, 636-642$ 


\section{Inhaltsverzeichnis}

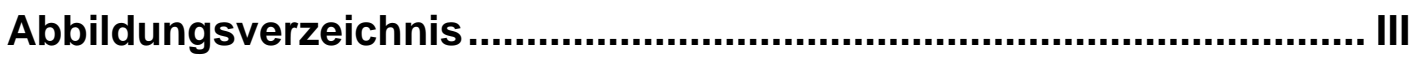

Tabellenverzeichnis .................................................................................

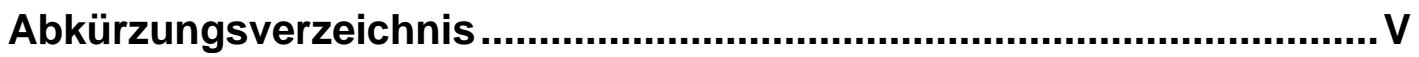

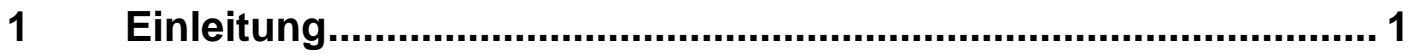

$1.1 \quad$ Dentale Erosionen ......................................................................

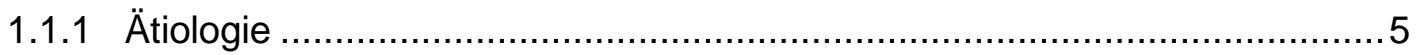

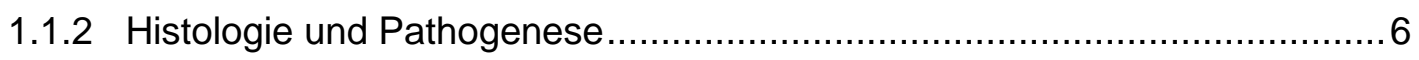

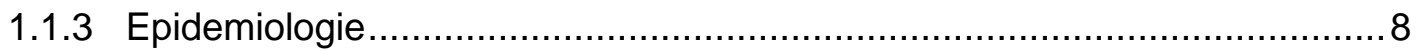

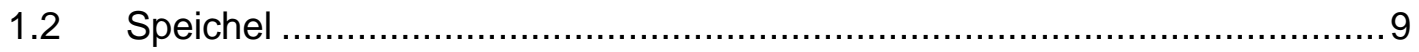

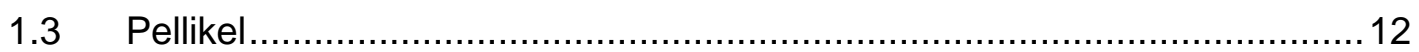

1.3.1 Bildung und Bestandteile der Pellikel.................................................. 12

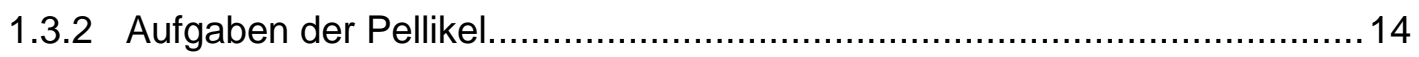

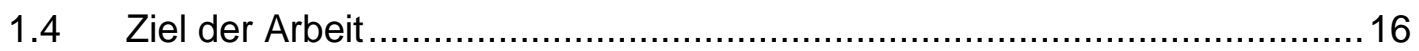

2 Material und Methoden .............................................................. 17

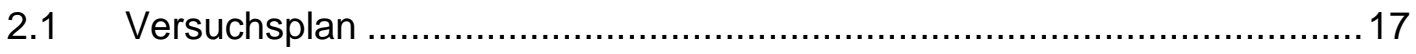

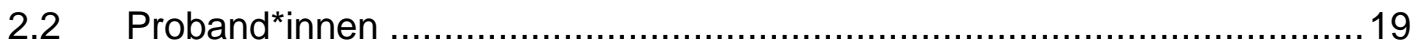

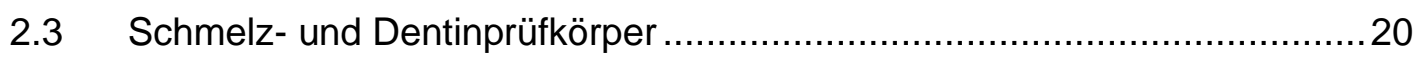

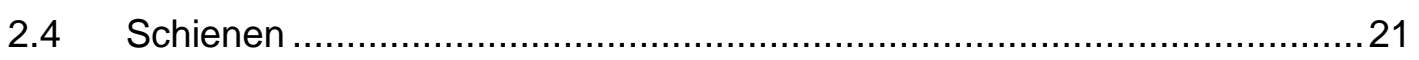

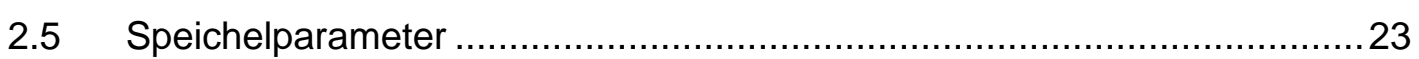

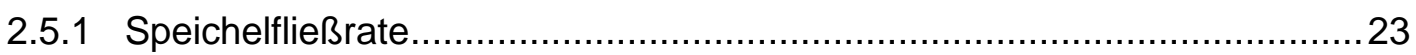

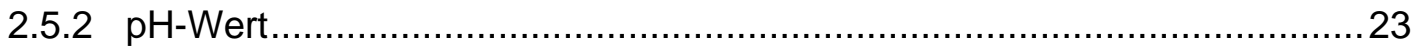

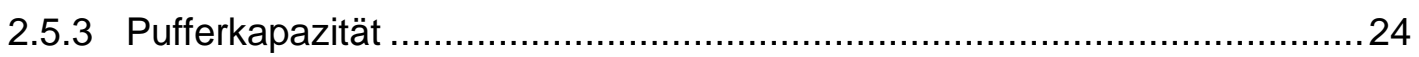

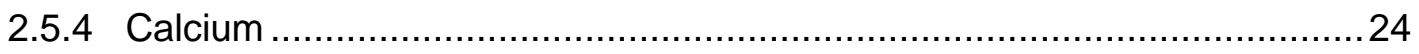

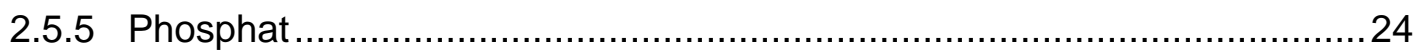

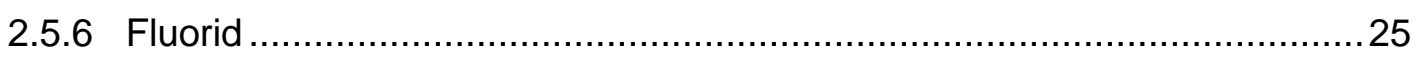

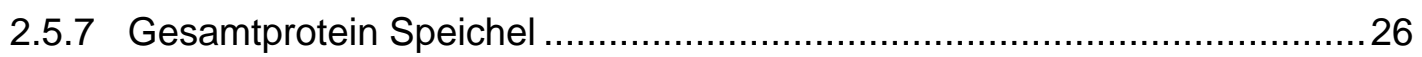

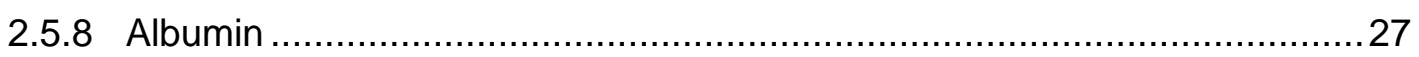

2.6 Bestimmung der durch Erosion freigesetzten Calcium-Ionen.....................28

2.7 Gesamtprotein in der Pellikel...........................................................29

2.8 Statistische Auswertung ......................................................................

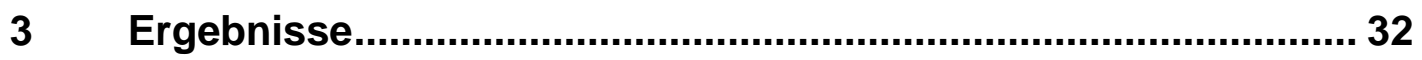

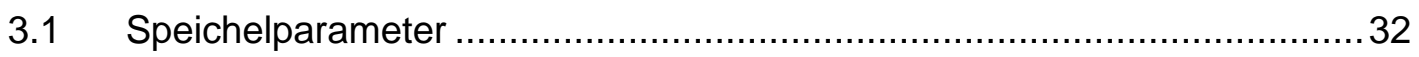

3.2 Calciumfreisetzung aus erodierten Schmelz- und Dentinprüfkörpern..........34 
3.3 Proteinkonzentration der Pellikel ........................................................ 38

3.4 Einfluss der Speichelparameter auf die Calciumfreisetzung .....................40

3.5 Einfluss des Proteingehalts in der Pellikel auf die Calciumfreisetzung.......41

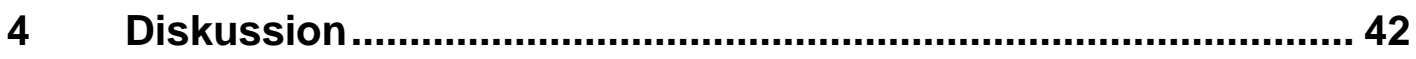

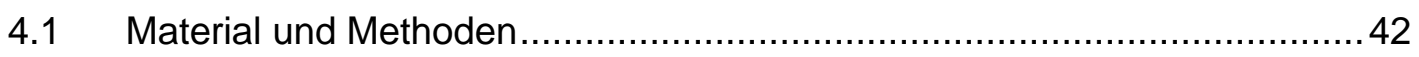

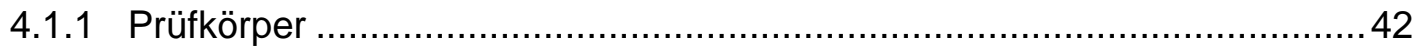

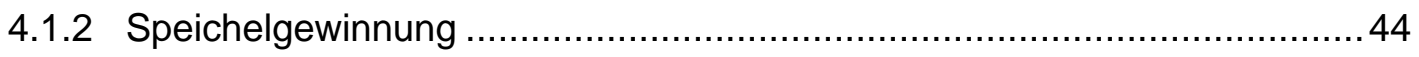

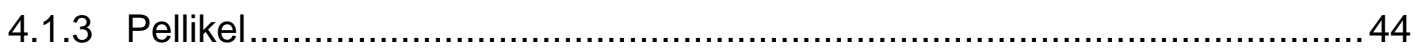

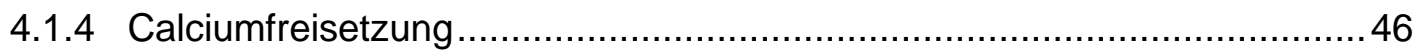

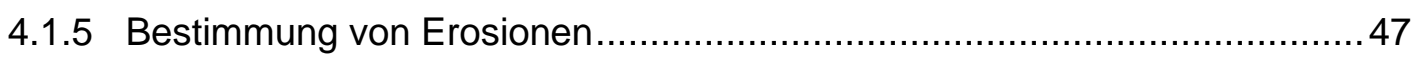

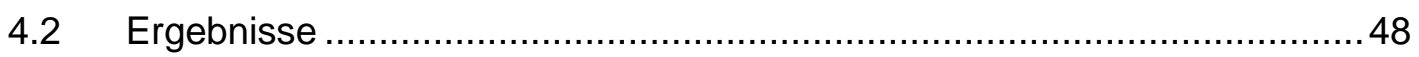

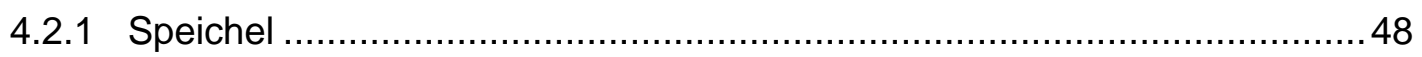

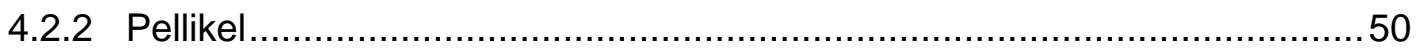

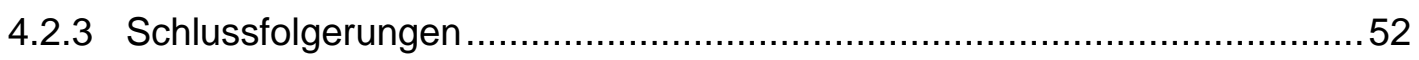

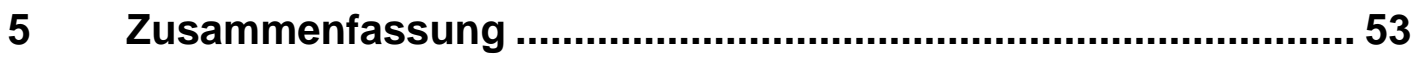

$6 \quad$ Literaturverzeichnis ................................................................ 54 


\section{Abbildungsverzeichnis}

Abbildung 2.1: Versuchsablauf .18

Abbildung 2.2: Modell mit Schiene und Prüfkörpern ....................................21

Abbildung 2.3: Schiene mit Prüfkörpern.

Abbildung 3.1: Säureinduzierte Calciumfreisetzung aus Schmelz von getragenen Prüfkörpern im Vergleich zur Kontrolle.

Abbildung 3.2: Säureinduzierte Calciumfreisetzung aus Dentin von getragenen

Prüfkörpern im Vergleich zur Kontrolle. 35

Abbildung 3.3: Säureinduzierte Calciumfreisetzung aus Schmelz. 36

Abbildung 3.4: Säureinduzierte Calciumfreisetzung aus Dentin...... 37

Abbildung 3.5: Proteingehalt der Pellikel auf Schmelz. 38

Abbildung 3.6: Proteingehalt der Pellikel auf Dentin. 39 


\section{Tabellenverzeichnis}

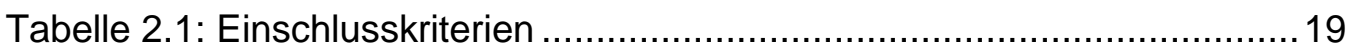

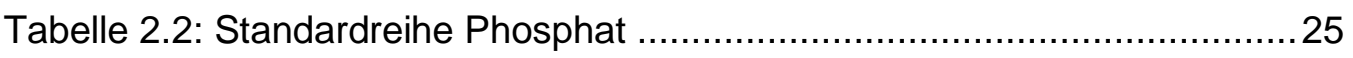

Tabelle 2.3: Standardreihe Gesamtprotein Speichel...................................26

Tabelle 2.4: Standardreihe Calcium bei Erosion ...........................................28

Tabelle 2.5: Standardreihe Gesamtprotein Pellikel ....................................... 30

Tabelle 3.1: Speichelparameter (Mittelwert \pm Standardabweichung) in stimulierten und unstimulierten Speichelproben aller

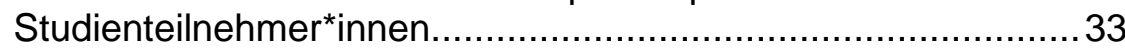

Tabelle 3.2: Einfluss der Speichelparameter auf die Calciumfreisetzung ( $p$ Werte der Pearson-Korrelationen) .......................................... 40 


\section{Abkürzungsverzeichnis}

slgA sekretorisches Immunglobulin A

TEM Transmissionselektronenmikroskop 


\section{$1 \quad$ Einleitung}

Zahnhartsubstanzverluste lassen sich in chemisch-physikalische (erosive Zahnhartsubstanzverluste) oder rein physikalische Prozesse (Abrasion und Attrition) unterscheiden. Unter dem Begriff der Erosion versteht man den chemischen Prozess durch direkte Säureeinwirkung - ohne das Vorhandensein von Mikroorganismen - auf der Zahnoberfläche (Schlueter et al. 2020). Davon abgrenzen lassen sich Abrasionen und Attritionen. Unter dem Begriff der Abrasion versteht man die Abnutzung der Zahnhartsubstanz durch Abrieb mit Fremdstoffen (Addy und Shellis 2006). Bei der Attrition kommt es durch Kontakte benachbarter und/oder antagonistischer Zahnflächen zur Abnutzung der Zahnhartsubstanz (Addy und Shellis 2006). Klinisch kommt es häufig zu einem Zusammenwirken von Erosionen sowie Abrasionen und/oder Attritionen auf die Zahnhartsubstanz. Dies wird unter dem Begriff des erosiven Zahnhartsubstanzverlustes beschrieben (Huysmans et al. 2011).

Zu den extrinsischen Faktoren, die dentale Erosionen hervorrufen, zählen unter anderem säurehaltige Nahrungsmittel oder Medikamente (Zero 1996). Zu den intrinsischen Faktoren zählt die häufige Benetzung der Zahnoberflächen durch Magensäure oder sauren Mageninhalt, z. B. ausgelöst durch Reflux oder Bulimia nervosa (Bartlett 2006).

Das Auftreten erosiver Zahnhartsubstanzverluste ist in der Bevölkerung weit verbreitet. So kann in allen Altersgruppen und Bevölkerungsschichten eine zunehmende Prävalenz erosiver Zahnhartsubstanzverluste verzeichnet werden (Dugmore und Rock 2004; Jaeggi und Lussi 2014; Schlueter und Luka 2018). Es bestehen Zusammenhänge zwischen Lebensstil, Ernährungsgewohnheiten oder sozioökonomischen Bedingungen und dem Vorkommen erosiver Zahnhartsubstanzdefekte (van Rijkom et al. 2002; Bardsley et al. 2004; Salas et al. 2017). Auch ethnologische Faktoren könnten einen Einfluss haben. Bei europäischen Kindern ließ sich im Vergleich zu asiatisch-stämmigen Kindern vermehrt erosive Zahnhartsubstanzverluste diagnostizieren (Dugmore und Rock 2003).

Des Weiteren scheint es geschlechtsspezifische Unterschiede hinsichtlich der 
Ausprägung erosiver Zahnhartsubstanzverluste zu geben (Hasselkvist et al. 2010; Uhlen et al. 2016a). Studien zeigten, dass erosive Zahnhartsubstanzdefekte häufiger bei Jungen und Männern vorkommen als beim weiblichen Geschlecht (Jaeggi und Lussi 2014; Tschammler et al. 2016). Eine mögliche Ursache dafür könnte der häufigere Konsum von Fruchtsäften und Softdrinks bei Jungen gegenüber Mädchen sein (Gose et al. 2016). Es werden allerdings auch biologische Faktoren diskutiert, die die geschlechtsspezifischen Unterschiede erklären könnten.

Das individuelle Vorkommen von erosiven Zahnhartsubstanzverlusten ist jedoch sehr unterschiedlich und könnte ebenfalls von der Pellikel- und Speichelzusammensetzung beeinflusst werden (Bruvo et al. 2009; Uhlen et al. 2016b).

Die Pellikel entsteht durch Speichelbenetzung der Zahnoberfläche in der Mundhöhle. Es bildet sich zunächst eine dünne Proteinschicht (Lendenmann et al. 2000). Es konnte in Studien gezeigt werden, dass sich die Proteinzusammensetzung der Pellikel bei Patient*innen mit und ohne erosiven Zahnhartsubstanzdefekten unterscheidet (Carpenter et al. 2014; Mutahar et al. 2017). Bei Patient*innen mit erosiven Zahnhartsubstanzdefekten wurden im Vergleich zur Kontrollgruppe bis zu $35 \%$ weniger Statherin und bis zu $50 \%$ weniger Calcium in der Schmelzpellikel gefunden (Carpenter et al. 2014). Des Weiteren wurde eine signifikant niedrigere Gesamtproteinkonzentration sowie weniger Statherin an erodierten Zahnoberflächen verglichen mit gesunden Zahnoberflächen in den selben Testpersonen festgestellt (Mutahar et al. 2017). Auch die Mineralkonzentration des Speichels, besonders das Verhältnis zwischen Speichelproteinen und Speichelionen, beeinflusst die erosionsschützende Wirkung einer Pellikel (Baumann et al. 2016).

Die Zusammensetzung des Speichels, sowie seine Fließrate, beeinflussen die Entstehung erosiver Zahnhartsubstanzverluste (Zero et al. 2006; Wetton et al. 2007; Hannig et al. 2009; Buzalaf et al. 2012). So gehen einige Speichelproteine Bindungen mit Calciumphosphatsalzen ein und verhindern dadurch die Präzipitation dieser Salze (Moreno et al. 1979; Hay et al. 1982). Je höher die Speichelfließrate ist, desto schneller wird Säure abgepuffert und abtransportiert (Hara und Zero 2014). 
In den Studien von Prodan et al. (2015) und Li-Hui et al. (2016) wurden geschlechtsspezifische Unterschiede in der Speichelzusammensetzung und Speichelfließrate gefunden. Die Fließrate (Li-Hui et al. 2016), der pH-Wert (Prodan et al. 2015; Li-Hui et al. 2016), die Pufferkapazität und die Proteinkonzentration (Prodan et al. 2015) waren bei Frauen niedriger als bei Männern. Außerdem wurden in einigen Studien geschlechtsspezifische Unterschiede hinsichtlich der Proteinzusammensetzung des Speichels gefunden (Srivastava et al. 2008; Murr et al. 2017).

Ziel dieser Studie war es daher zu untersuchen, ob geschlechtsspezifische Speichelparameter einen Einfluss auf die Pellikelzusammensetzung von Frauen und Männern haben und ob dies Auswirkungen auf die erosionsprotektive Wirkung der Pellikel hat.

\subsection{Dentale Erosionen}

Erosive Zahnhartsubstanzdefekte sind Zahnhartsubstanzverluste, die durch direkte Säureeinwirkung auf die Zahnoberfläche hervorgerufen werden (Ganss et al. 2014). Klinisch lassen sich durch Säure hervorgerufene Zahnhartsubstanzverluste von rein mechanisch induzierten Zahnhartsubstanzdefekten nur bedingt abgrenzen, da es häufig gerade im okklusalen Bereich der Zahnoberflächen zu Überlagerungen kommt. Insofern wird für das klinische Bild der Erosion häufig der Begriff erosiver Zahnhartsubstanzverlust gewählt, um die Interaktion von Erosion, Abrasion und Attrition unter klinischen Bedingungen zu beschreiben.

Davon abgrenzen lässt sich die Entstehung kariöser Läsionen. Hierbei kommt es zur Ansammlung von Mikroorganismen in einem die Zahnoberfläche bedeckenden Biofilm, der zugeführte niedermolekulare Kohlenhydrate zur Energiegewinnung metabolisiert. Die Endprodukte sind organische Säuren, die zu einem Abfall des $\mathrm{pH}$-Wertes im Biofilm führen. Dies führt bei längerer Säureeinwirkung auf die Zahnhartsubstanz zu einem Mineralverlust der 
Zahnoberfläche. Der kritische pH-Wert liegt hierbei für Schmelz um 5,5 und für Dentin um 6,5 (Meurman und ten Cate 1996).

Zunächst entsteht eine initiale Karies. Hierbei diffundiert die organische Säure in den Zahnschmelz. Im Schmelzinneren dissoziiert die Säure und gibt WasserstoffIonen ab. Diese Wasserstoff-lonen greifen die Schmelzkristalle an und es werden unter anderem Calcium-, Carbonat-. Fluorid- und Phosphat-Ionen freigesetzt. Diese Ionen diffundieren aufgrund ihres Konzentrationsgradienten zur Schmelzoberfläche hin, wobei sich die Diffusionsgeschwindigkeit zur Oberfläche hin reduziert, da der Diffusionsgradient zum Speichel geringer ist. Es kommt zu einer Repräzipitation der Calcium- und Phosphat-Ionen. Diese lonen bilden neue Kristalle oder lagern sich an der Oberfläche geschädigter Kristalle an. Dadurch entsteht zunächst eine pseudointakte Oberfläche. Bei Entfernung der kariogenen Noxen kann die kariöse Schmelzläsion arretieren und remineralisieren. Hält der Demineralisationsprozess aufgrund weiterer Zufuhr von Kohlenhydraten und somit Säureproduktion an, kommt es zu einem Calcium- und Phosphatverlust. Dies kann im weiteren Verlauf zu einem Voranschreiten der Demineralisation führen und sich bis ins Dentin ausweiten.

Bei einer dentalen Erosion führt die direkte Einwirkung einer Säure mit niedrigem pH-Wert zur Demineralisation der äußeren Schmelzschicht (Lussi und Carvalho 2014). Je niedriger der pH-Wert der Säure ist, desto höher ist ihr Erosionspotenzial. Bei häufiger und langandauernder Säureeinwirkung auf die Zahnoberfläche kommt es dann zum Zahnhartsubstanzverlust (Lussi und Hellwig 2014). Zunächst ist nur der Schmelz betroffen, im weiteren Verlauf kann sich der Zahnhartsubstanzverlust auch auf das Dentin ausdehnen. In diesem Stadium leiden Patient*innen häufig unter Hypersensibilitäten sowie unter funktionellen und ästhetischen Einschränkungen.

Erosive Zahnhartsubstanzverluste lassen sich aufgrund der Säurequelle in exogen und endogen induzierte Defekte unterteilen. Exogen verursachte erosive Zahnhartsubstanzverluste sind überwiegend auf den Labialflächen der Frontzähne sowie auf den Bukkalflächen lokalisiert. Endogen induzierte erosive Zahnhartsubstanzverluste finden sich hingegen häufig auf den Palatinalflächen 
der Oberkieferfrontzähne und im späteren Verlauf auch auf den okklusalen Zahnoberflächen.

\subsection{1 Ätiologie}

Zu den Ursachen der extrinsischen Säurezufuhr zählen der vermehrte Konsum von säurehaltigen Nahrungsmitteln (z. B. Zitrusfrüchte, Essig und Fruchtbonbons) und Getränken (z. B. Fruchtsaftgetränke, Softdrinks, Sportlergetränke und Wein), die Einnahme bestimmter Medikamente (z. B. Acetylsalicylsäure, Eisentabletten und Vitamin C Präparate) und die beruflich bedingte Säureexposition (z. B. bei Profischwimmern oder Weintestern, sowie bei Arbeiten mit sauren Dämpfen aus Batterie-, Galvanisierungs- oder Munitionsfabriken) (Zero 1996; Wiktorsson et al. 1997; Lussi et al. 2004; Wiegand und Attin 2007; Buczkowska-Radlińska et al. 2013).

Die Ernährung ist in den westlichen Gesellschaften als wichtigster Faktor für die Entstehung dentaler Erosionen anzusehen (Zero 1996). Verschiedene Studien belegen, dass die regelmäßige Aufnahme von Lebensmitteln oder säurehaltigen Getränken mit niedrigem pH-Wert ein erhöhtes Risiko für die Ausbildung erosiver Zahnhartsubstanzverluste darstellt. Die Studie von Järvinen et al. (1991) zeigte ein signifikant erhöhtes Risiko für das Auftreten von erosiven Zahnhartsubstanzverlusten, wenn es zu einer mehr als zweimal täglichen Aufnahme von Zitrusfrüchten sowie täglichem Trinken von Softdrinks und wöchentlicher Konsumierung von Essig oder Sportlergetränken kam. Auch Johansson et al. (2002) stellten in ihrer Studie fest, dass die Art und Häufigkeit der Nahrungsaufnahme einen Einfluss auf die Ausprägung säurebedingter Zahnhartsubstanzverluste haben. So führten bestimmte Trinkgewohnheiten, wie z. B. schluckweises Trinken oder intensives Spülen über einen langen Zeitraum im Vergleich zu einem einmaligen Konsum zu einem länger anhaltenden $\mathrm{pH}$ Wert-Abfall in der Mundhöhle. Auch der häufige Konsum von Wein birgt aufgrund seines niedrigen pH-Wertes zwischen 3,0 und 4,0 ein erhöhtes Erosionspotential. Nahrungsmittel, die einen niedrigen $\mathrm{pH}$-Wert haben, aber einen hohen Gehalt an Calcium- und Phosphat-Ionen besitzen, wiesen hingegen kein erhöhtes 
Erosionspotenzial auf (Barbour und Lussi 2014). Hierzu zählen z. B. Buttermilch oder Joghurt.

Medikamente stellten einen weiteren Risikofaktor zur Entstehung erosiver Zahnhartsubstanzverluste dar (Thomas et al. 2015). Nach Hellwig und Lussi (2014) kann die regelmäßige Einnahme von Acetylsalicylsäure das Auftreten erosiver Zahnhartsubstanzdefekte begünstigen. Medikamente, wie z. B. Antihistaminika, Antiemetika, Beruhigungsmittel oder Medikamente gegen Morbus Parkinson, können als Nebenwirkung eine reduzierte Speichelfließrate hervorrufen, die die Entstehung von erosiven Zahnhartsubstanzdefekten ebenfalls begünstigt.

Das häufige Auftreten von Magensäure in der Mundhöhle ist die Hauptursache für intrinsisch hervorgerufene erosive Zahnhartsubstanzverluste. Ursache hierfür sind überwiegend Erkrankungen wie Bulimia nervosa, gastro-ösophagealerReflux oder chronischer Alkoholabusus (Smith und Robb 1989; Bartlett 2006; Moazzez und Bartlett 2014). Der pH-Wert von Magensäure liegt bei 1,0 bis 1,5. Das Ausmaß erosiver Zahnhartsubstanzverluste ist aufgrund des niedrigeren $\mathrm{pH}$ Wertes der Magensäure im Vergleich zu extrinsischen Säuren deutlich größer (Bartlett 2006; Uhlen et al. 2014). Bei an Bulimia nervosa erkrankten Patient*innen kommt es vermehrt zu erosiven Zahnhartsubstanzdefekten, da diese Patient*innen häufig erbrechen (Johansson et al. 2012; Hermont et al. 2014; Uhlen et al. 2014). Eine weitere Ursache für erosive Zahnhartsubstanzverluste bei essgestörten Patient*innen ist eine erniedrigte Speichelfließrate (Rytömaa et al. 1998). Bei Alkoholikern entstehen erosive Defekte durch die Kombination aus Erbrechen und dem regelmäßigen Konsum potenziell säurehaltiger Getränke.

\subsubsection{Histologie und Pathogenese}

Die Erosion im Schmelz läuft im Gegensatz zur Erosion im Dentin aufgrund einer unterschiedlichen Struktur und Zusammensetzung der Gewebe verschieden ab. Schmelz setzt sich aus ca. $93 \%$ Hydroxylapatit und zwischen 1,5 und $4 \%$ Wasser zusammen. Des Weiteren besteht es aus organischen Substanzen. Der 
Mineralgehalt im Dentin liegt bei $70 \%$ und der Anteil an organischer Substanz bei $20 \%$, der Rest ist Wasser.

Durch direkte Säureeinwirkung auf die Schmelzoberfläche werden Calcium- und Phosphat-lonen aus dem Hydroxylapatitkristallgitter herausgelöst. Initial kommt es zu einem partiellen Mineralverlust der Oberfläche wodurch eine „erweichte“ Schmelzschicht entsteht und die Mikrohärte herabgesetzt ist. Hierbei tritt noch kein Zahnhartsubstanzverlust auf. Die Dicke der „erweichten“ Schmelzschicht variiert zwischen 0,2 bis 3 m (Amaechi et al. 1999; Wiegand und Attin 2007; Voronets und Lussi 2010). Dies führt zu einer Veränderung der Schmelzstruktur und zum Verlust der Perikymatien. Histologisch weist die Zahnoberfläche nach Säurekontakt eine Honigwabenstruktur auf, die an das Ätzmuster, welches bei der Schmelz-Ätz-Technik entsteht, erinnert (Meurman und Frank 1991; Ganss et al. 2014). Klinisch lassen sich lokal begrenzte mattglänzende Zahnoberflächen diagnostizieren. Weitere Säureangriffe führen zu einem Voranschreiten des Mineralverlustes. Durch die herabgesetzte Mikrohärte ist die Widerstandsfähigkeit der Oberfläche gegenüber physikalischen Angriffen, wie Attrition und Abrasion (Jaeggi und Lussi 1999; Voronets et al. 2008), reduziert. Dies begünstigt das Voranschreiten der Läsion.

Im Dentin wird bei einem Säureangriff das Hydroxylapatit gelöst, die organische Dentinmatrix bleibt jedoch erhalten (Ganss et al. 2014). Zunächst lösen sich das peri- und intertubuläre Dentin bei einem Säureangriff ähnlich schnell. Nach kurzer Zeit findet sich nur noch intertubuläres Dentin, das peritubuläre Dentin hat sich vollständig gelöst (Kinney et al. 1995). Der Mineralverlust verlangsamt sich jedoch deutlich mit einer zunehmenden Dicke der freiliegenden Kollagenschicht im Dentin (Ganss et al. 2009). Möglicherweise reduziert die Kollagenschicht den Säureaustausch, was zu einer Verlangsamung der Demineralisation führt (Lussi et al. 2011).

Der Zahnhartsubstanzverlust ist abhängig von der Dauer und Häufigkeit der Säureeinwirkung auf die Zahnoberfläche.

Erosive Zahnhartsubstanzdefekte können zu einem vollständigen Verlust der Zahnmorphologie, sowie Verlust der Kronenhöhe führen (Lussi et al. 2006). 


\subsubsection{Epidemiologie}

Studien belegten, dass erosive Zahnhartsubstanzverluste alle Altersgruppen betreffen. Die Prävalenz bei Vorschulkindern liegt zwischen $6 \%$ und $50 \%$, bei Jugendlichen (9-17 Jahre) zwischen $11 \%$ und $100 \%$ und bei Erwachsenen zwischen $4 \%$ und $82 \%$ (Jaeggi und Lussi 2014). In der Übersichtsarbeit von Schlueter und Luka (2018) liegt die Prävalenz bei bleibenden Zähnen zwischen $20 \%$ und $45 \%$ und bei Milchzähnen zwischen $30 \%$ und $50 \%$.

Es konnte in mehreren Studien eine Zunahme erosiver Zahnhartsubstanzdefekte bei Kindern und Jugendlichen beobachtet werden (Dugmore und Rock 2003; Jaeggi und Lussi 2014; Al-Ashtal et al. 2017). So zeigten Dugmore und Rock (2003) in ihrer Studie, dass von 1753 untersuchten 12-jährigen Kindern 56,3 \% säurebedingte Zahnhartsubstanzdefekte aufwiesen. Zwei Jahre später wurden 1308 dieser Kinder erneut untersucht, und das Auftreten erosiver Zahnhartsubstanzverluste war auf 64,1\% angestiegen. Bei 12,3\% der Kinder, die mit 12 Jahren keine erosiven Zahnhartsubstanzdefekte hatten, wurden nach zwei Jahren Defekte diagnostiziert.

Jungen weisen häufig signifikant mehr erosive Defekte an den Zähnen auf als Mädchen (Hasselkvist et al. 2010; Jaeggi und Lussi 2014; Uhlen et al. 2016a). Ein Grund dafür könnte ein erhöhter Konsum von Fruchtsäften und Softgetränken sein (Hasselkvist et al. 2010; Gose et al. 2016). Ebenso beeinflussen die Ernährungsweise, der Lebensstil und unter anderem auch die soziale Herkunft das Ausmaß erosiver Zahnhartsubstanzverluste (Milosevic et al. 1994; van Rijkom et al. 2002; Bardsley et al. 2004; Tschammler et al. 2016). In der Studie von Maharani et al. (2019) konnte das Vorkommen von erosiven Zahnhartsubstanzverlusten mit einem niedrigen Bildungsstand der Mutter in Verbindung gebracht werden. Auch die Studie von Dugmore und Rock (2004) kam zu dem Ergebnis, dass bei sozial benachteiligten Kindern vermehrt erosive Zahnhartsubstanzverluste auftreten. 


\subsection{Speichel}

Speichel besteht zu über $99 \%$ aus Wasser, der Rest setzt sich aus anorganischen und organischen Substanzen zusammen (Humphrey und Williamson 2001; Dodds et al. 2005). Zu den anorganischen Bestandteilen gehören unter anderem Natrium-, Kalium-, Calcium-, Magnesium-, Bikarbonat-, Phosphat- und Fluorid-Ionen. Die organischen Bestandteile umfassen Enzyme, Glykoproteine, Muzine, Harnstoff, sowie über 400 verschiedene weitere Proteine (Humphrey und Williamson 2001; Liu und Duan 2012). Die wichtigsten Proteine sind unter anderem a-Amylase, Histatin, Cystatin, Lactoferrin, Lysozyme, prolinreiche Proteine, Muzine, sowie Albumin, Transferrin und sekretorisches Immunglobulin A (slgA) (Tenovuo 1998; Dodds et al. 2005; Chiappin et al. 2007). Einige Speichelproteine wie z. B. Statherine oder prolinreiche Proteine verringern das Ausmaß säurebedingter Zahnhartsubstanzverluste (Siqueira et al. 2007), in dem sie eine Bindung mit Calciumphosphatsalzen eingehen. Dies führt zu einer Vermeidung der Präzipitation dieser Salze (Moreno et al. 1979; Hay et al. 1982; Aoba et al. 1984; Buzalaf et al. 2012).

Man unterscheidet zwischen Ruhespeichel (ohne äußere Stimulation) und stimuliertem Speichel (mit äußerer Stimulation).

Der unstimulierte Speichel hat eine Fließrate von 0,3 bis $0,4 \mathrm{ml} / \mathrm{min}$ mit hoher Variabilität und unterliegt einem zirkadianen Rhythmus (Dawes 1974; Edgar 1990). Der Höhepunkt der Ruhespeichelproduktion liegt am Nachmittag, wohingegen die Speichelproduktion nachts nahezu eingestellt wird (Dawes 1974).

Stimulierter Speichel, der durch die Stimulation der Drüsenaktivität (z. B. durch Geruchs-, Geschmacks- oder mechanische Reize) produziert wird, hat eine Fließrate von 1 bis $3 \mathrm{ml} / \mathrm{min}$. Der stimulierte Speichel wird überwiegend aus der Glandula parotis sezerniert (Edgar 1992; Dodds et al. 2005).

Die Fließrate trägt zur Reduktion erosiver Zahnhartsubstanzdefekte bei (Järvinen et al. 1991; Meurman et al. 1994; Tenovuo 1997; Rytömaa et al. 1998). Je höher die Fließrate ist, desto mehr organische und anorganische Substanzen sind in der Mundhöhle vorhanden, die die Zahnoberfläche vor initialen Säureangriffen schützen können. Darüber hinaus kann die Säure schneller abgepuffert und 
abtransportiert werden (Hara und Zero 2014).

Es konnte in Studien belegt werden, dass ein verminderter Speichelfluss die Entstehung erosiver Zahnhartsubstanzdefekte begünstigt (Järvinen et al. 1991; Rytömaa et al. 1998; Jensdottir et al. 2013). In einer weiteren Studie von Zwier et al. (2013) zeigte sich bei Personen mit erosiven Zahnhartsubstanzdefekten im Vergleich zur Kontrollgruppe eine verringerte Fließrate.

Der Speichel verfügt über drei Puffersysteme, den Bikarbonatpuffer, den Phosphatpuffer und den Proteinpuffer (Larsen und Pearce 2003; Dodds et al. 2005). Der Bikarbonatpuffer spielt eine führende Rolle bei der schnellen Neutralisation der Mundhöhle bei Säureangriffen.

Moazzez et al. (2004) stellten in ihrer klinischen Studie bei Patient*innen, die am gastro-ösophagealem-Reflux erkrankt sind, eine verminderte Pufferkapazität im Speichel fest. In der Studie von Corrêa et al. (2012) zeigte der Speichel von Patient*innen mit gastro-ösophagealem-Reflux und säurebedingten Zahnhartsubstanzverlusten ebenfalls eine verminderte Pufferkapazität.

Des Weiteren konnte in Studien ein geschlechtsspezifischer Unterschied in der Speichelzusammensetzung festgestellt werden. Prodan et al. (2015) zeigten in ihrer Studie im Ruhespeichel erniedrigte Werte für die Pufferkapazität, den $\mathrm{pH}$ Wert, den Proteingehalt, den Gehalt an Muzin 5B und slgA sowie die Chitinaseaktivität bei Probandinnen im Vergleich zu Probanden. Die Konzentration von Muzin 7 und die Lysozymaktivität waren bei Frauen im Vergleich zu Männern erhöht. Auch Li-Hui et al. (2016) belegten einen erniedrigten $\mathrm{pH}-$ Wert sowie eine erniedrigte Fließrate bei Frauen.

Für Speichelproteine wurde in der Literatur gezeigt, dass es altersabhängige und geschlechtsspezifische Unterschiede gibt (Srivastava et al. 2008; Fleissig et al. 2010; Bocklandt et al. 2011). In der Studie von Cabras et al. (2009), in der der Speichel von 67 Proband*innen im Alter zwischen 3 und 44 Jahren in Bezug auf prolinreiche Proteine, Phosphoproteine, Statherin, prolinreiche Peptide, Cystatin und Histatin mittels Hochleistungsflüssigkeitschromatographie analysiert wurde, zeigten sich altersabhängige Unterschiede. Die Studienteilnehmer*innen wurden in fünf Altersgruppen eingeteilt. Prolinreiche Peptide wurden überwiegend in der Altersklasse zwischen 24 und 44 Jahren gefunden, wohingegen sie zwischen 3 
und 9 Jahren kaum auftraten. Die Gruppe der 10 bis 12-jährigen Proband*innen zeigte im Vergleich zur Gruppe der 3 bis 5 Jahre alten Proband*innen eine signifikant höhere Konzentration an Peptid P-D, Peptid P-F, Peptid P-H, Peptid P-J und prolinreichem Peptid IB-1. Das prolinreiche Peptid II-2 wurde vermehrt bei über 12-jährigen gefunden. Bei der Gruppe der 6 bis 9-jährigen Proband*innen war die Konzentrationen an Histatin 3 1/24 und 3 1/25, prolinreichen Phosphoproteinen sowie von mono- und diphosphorylisiertem Cystatin S im Vergleich zu den übrigen Altersgruppen am geringsten. In der Gruppe der 3 bis 5 Jahre alten Kinder konnte im Vergleich zu den anderen Gruppen eine signifikant höhere Konzentration an Histatin 1 bestimmt werden (Cabras et al. 2009).

Xiao et al. (2017) identifizierten im unstimuliertem Speichel 82 Proteine, die geschlechtsspezifisch auftreten. Im stimulierten Speichel wurden keine geschlechtsspezifischen Proteine gefunden. 


\subsection{Pellikel}

Die Pellikel ist eine sich dauernd in ihrer Zusammensetzung verändernde dynamische semipermeable Biomembran (Rosan und Lamont 2000; Hannig und Joiner 2006). Ihre Struktur, Morphologie und Dicke ist abhängig von der Bildungszeit (Nyvad und Fejerskov 1987; Hannig 1999b), dem oralen Expositionsort, mechanischen Einflüssen wie z. B. Scherkräften der Zunge (Amaechi et al. 1999; Hannig 1999b) sowie interindividuellen Unterschieden (Finke et al. 2002; Hannig et al. 2004). Sie besteht zum größten Teil aus Speichelproteinen, Glykoproteinen, Enzymen, Kohlenhydraten und Fetten (Lendenmann et al. 2000). Die Pellikel nimmt eine wichtige Schutzfunktion gegenüber der Entstehung von säurebedingten Zahnhartsubstanzdefekten ein und übernimmt eine Schlüsselfunktion bezüglich der De- und Remineralisation sowie Lubrikation in der Mundhöhle (Siqueira et al. 2012).

\subsubsection{Bildung und Bestandteile der Pellikel}

Die Entstehung der Pellikel lässt sich in zwei Phasen aufteilen (Skjørland et al. 1995). Zunächst bildet sich innerhalb von Minuten eine dünne Pellikelschicht mit einer Dicke von 10 bis $20 \mathrm{~nm}$, die bis zu 30 min konstant bleibt (Lendenmann et al. 2000). Hannig (1999b) zeigte anhand transelektronenmikroskopischer Aufnahmen (TEM), dass die Basalschicht eine elektronendichte, feingranuläre Schicht mit homogener Struktur ist. Sie besteht überwiegend aus Speichelproteinen, die eine hohe Affinität zu Hydroxylapatit aufweisen und elektrostatische Verbindungen mit der Schmelzoberfläche eingehen (Hay 1973; Bennick et al. 1979; Hannig und Joiner 2006). Die Proteinadsorption an der Schmelzoberfläche wird durch Van-der-Waals-Kräfte und hydrophobe Wechselwirkungen hervorgerufen (Hannig und Joiner 2006; Hannig und Hannig 2009). Häufige Proteine in der initialen Pellikelschicht sind prolinreiche Proteine, Statherine, Histatine, Muzine, Amylase, Cystatin, Lysozym und Laktoferrin (Jensen et al. 1992; Lamkin et al. 1996; Vacca Smith und Bowen 2000; Li et al. 2004b; Hannig und Joiner 2006). Ebenfalls wurden Albumin, Carboanhydrase, slgA, IgG, IgM, muköses Glykoprotein und Glykosyltransferase in der frühen 
Pellikel gefunden (Vacca Smith und Bowen 2000; Li et al. 2004a; Hannig et al. 2005a). In der zweiten Phase nimmt die Dicke der Pellikelschicht durch die Adsorption von Protein-Aggregaten aus dem Speichel aufgrund von ProteinProtein-Interaktionen zu. Diese Protein-Aggregate und Micellen-ähnlichen Strukturen (Young et al. 1999) binden sich an noch unbedeckte Zahnoberflächen. Es entstehen sogenannte supramolekulare Pellikel-Vorläufer, welche im Laufe der Zeit mit der initial entstandenen hydrophoben Pellikelschicht zu einer strukturierten Proteinschicht interagieren (Vitkov et al. 2004).

Weitere Bestandteile der Pellikel sind Kohlenhydrate (Siqueira et al. 2012). Am häufigsten kommt Glukose vor, darüber hinaus findet man aber auch Fucose, Galaktose, Glukosamin und Mannose in der Pellikel (Sönju et al. 1974; Hannig und Joiner 2006). Ebenfalls enthält die Pellikel Lipide. Nach Hannig und Joiner (2006) sind die bedeutendsten unter innen die Glykolipide, neutrale Lipide wie Cholesterol und Triglyceride, sowie die Phospholipide. Lipide in der Pellikel hemmen die Bakterienadhäsion und schützen die Zahnoberfläche vor erosiven Angriffen (Reich et al. 2012).

Des Weiteren konnte an der initialen Pellikelschicht die Ansammlung von Bakterien belegt werden (Dige et al. 2007; Dige et al. 2009; Hannig und Hannig 2009; Gregoire et al. 2011). Für die Bakterienadhäsion sind häufig die Pellikelproteine wie z. B. Amylase, prolinreiche Proteine und Statherine verantwortlich, da sie spezifische Rezeptoren für die Interaktion mit Bakterien besitzen (Douglas 1994; Hannig und Hannig 2009).

Die Pellikeldicke schwankt nach bis zu zwei Stunden zwischen 20 und 500 nm sowie nach 24 Stunden zwischen 100 und 1300 nm (Hannig 1999b). Sie ist abhängig von der oralen Lokalisation. So wies die Pellikel in der Studie von Hannig (1999b) nach 120 min lediglich eine Dicke von 20 bis $80 \mathrm{~nm}$ auf palatinalen Zahnflächen auf. Nach 24 Stunden wies sie eine Dicke von 100 bis $200 \mathrm{~nm}$ auf. Die bukkale Pellikel hingegen wies nach 120 min bereits eine Dicke von 200 bis $700 \mathrm{~nm}$ und nach 24 Stunden von 1000 bis $1300 \mathrm{~nm}$ auf. Die bukkale Pellikel zeigte in TEM-Aufnahmen eine komplexe Ultrastruktur mit dichten granulären und globulären Bereichen, wohingegen die palatinale Pellikel eine homogene granuläre Struktur aufwies (Hannig 1999b). Diese Unterschiede sind 
Ursache einer unterschiedlichen Speichelbenetzung der Zahnoberflächen aufgrund der anatomischen Lage der Ausführungsgänge der Speicheldrüsen und dem Einwirken von Scherkräften ausgehend von der Zunge (Amaechi et al. 1999).

\subsubsection{Aufgaben der Pellikel}

Die Pellikel hat in der Mundhöhle einige wichtige Bedeutungen. Sie dient als Vorstufe für die Entstehung eines Biofilms auf der Zahnoberfläche und bildet unter anderem einen Gleitfilm zwischen Zahnhartsubstanz und angrenzenden Weichgeweben. Als Lubrikant erleichtert sie so den Sprech-, Schluck- sowie Kauvorgang (Tabak et al. 1982; Aguirre et al. 1989; Berg et al. 2003). Für diesen Gleiteffekt sind die Pellikelbestandteile Muzin, Statherin und prolinreiche Proteine verantwortlich (Douglas et al. 1991; Tabak 1995; Berg et al. 2004). Ebenso verringert die Pellikel Abrasionen, die durch Zähneputzen auf Schmelz- und Dentinoberflächen entstehen können (Joiner et al. 2008).

Des Weiteren weist die Pellikel antimikrobielle Eigenschaften auf. Hierfür verantwortlich sind unter anderem die Proteine Cystatin, Histatin, Lysozym und Myeloperoxidase. Überdies fanden sich in der Pellikel Proteine, die die Immunabwehr und Entzündungshemmung mit regulieren (Siqueira et al. 2007).

Darüber hinaus agiert die Pellikel als semipermeable Membran im De- und Remineralisationsprozess.

Die Pellikel fungiert als schützende Barriere vor Säureangriffen auf die Zahnoberfläche (Zahradnik et al. 1977; Meurman und Frank 1991; Hannig 1999b; Hannig und Balz 2001; Cheaib und Lussi 2011). Einige Proteine, wie Histatin oder Muzin, haben einen protektiven Einfluss auf Demineralisationsprozesse nach Säureangriffen im Schmelz (Siqueira et al. 2010; Delecrode et al. 2015a). Möglicherweise übernimmt die Protein-Protein-Interaktion eine wichtige Funktion in der Effektivität der pellikelschützenden Wirkung vor säurebedingter Demineralisation im Zahnschmelz (Cheaib und Lussi 2011).

Der erosive Schutz der Pellikel auf Dentin wurde nur in wenigen Studien untersucht (Hara et al. 2006; Wetton et al. 2006; Hannig et al. 2007). Hara et al. 
(2006) konnten keine protektive Wirkung der Pellikel für Dentin feststellen. Wetton et al. (2006) zeigten hingegen schon nach 2-minütiger Pellikelbildung einen protektiven Schutz gegenüber einem 10-minütigen Zitronensäureangriff. Die Pellikel auf der Schmelzoberfläche zeigte jedoch eine bessere Schutzfunktion (Wetton et al. 2006). Ähnliche Ergebnisse lieferten die Untersuchungen von pellikelbedeckten Schmelz- und Dentinprüfkörpern nach Inkubation in unterschiedlichen Inkubationsmedien (Wiegand et al. 2008a). In dieser Studie zeigten pellikelbedeckte Schmelzprüfkörper unabhängig von der Art der Säure bei einem konstanten pH-Wert von 2,6 eine zweifach bessere Schutzfunktion bei Säureangriffen gegenüber pellikelbedeckten Dentinprüfkörpern (Wiegand et al. 2008a). 


\subsection{Ziel der Arbeit}

Ziel dieser In-situ-Studie ist es zu untersuchen, ob es geschlechtsspezifische Unterschiede in der Speichel- und/oder Pellikelzusammensetzung gibt und ob diese Auswirkungen auf die erosionsprotektive Wirkung der Pellikel haben.

Dafür werden verschiedene Speichelparameter (Fließrate, pH-Wert, Pufferkapazität, Calcium-, Phosphat-, Fluorid-, Gesamtprotein- und Albumingehalt), der Proteingehalt in der Pellikel und die säureinduzierte Calciumfreisetzung aus in situ getragenen Prüfkörpern untersucht. Als Nullhypothese wird postuliert, dass die säureinduzierte Calciumfreisetzung aus pellikelbedeckten Schmelz- und Dentinprüfkörpern zwischen Männern und Frauen nicht signifikant unterschiedlich ist. 


\section{Material und Methoden}

\subsection{Versuchsplan}

Für diese Studie wurde vorab ein Ethikantrag gestellt und unter der Nummer 7/10/15 genehmigt. Das Studienprotokoll wurde in einer Studiendatenbank registriert (ClinicalTrials.gov: NCT02780973).

Insgesamt nehmen an der Studie 50 gesunde Proband*innen teil, davon sind 25 weiblich und 25 männlich. Die Proband*innen geben an zwei unterschiedlichen Tagen zwischen 9 Uhr und 10 Uhr je eine Probe unstimulierten und stimulierten Speichels $a b$, um zu überprüfen, ob die Einschlusskriterien erfüllt sind. Die Speichelfließrate, der pH-Wert, die Pufferkapazität sowie der Albumin-, Calcium, Gesamtprotein-, Fluorid- und Phosphatgehalt der Speichelproben wird untersucht. Am ersten Versuchstag wird zusätzlich noch eine Unterkieferabformung vorgenommen. Am zweiten Versuchstag wird eine Trägerschiene mit je drei bovinen Schmelz- und Dentinprüfkörpern in zufälliger Anordnung für 120 min intraoral getragen. Je zwei in der Mundhöhle getragene Schmelz- und Dentinprüfkörper werden anschließend für $60 \mathrm{~s}$ in $1 \mathrm{ml} \mathrm{HCl}(\mathrm{pH}$ Wert 2,6; $c=0,0025 \mathrm{~mol} / \mathrm{l}$ ) erodiert. Die Kontrollgruppe besteht aus je 30 pellikelfreien Schmelz- und Dentinprüfkörpern, die erodiert werden. Anschließend werden die durch Erosion freigesetzten Calcium-Ionen mittels der Arsenazo III Methode photometrisch quantifiziert.

Zur Bestimmung des Gesamtproteingehalts in der Pellikel wird je ein getragener

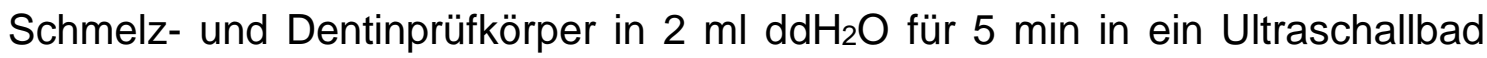
gegeben. Nachfolgend wird der Gesamtproteingehalt in der Suspension bestimmt.

Der Versuchsplan ist in Abbildung 2.1 dargestellt. 


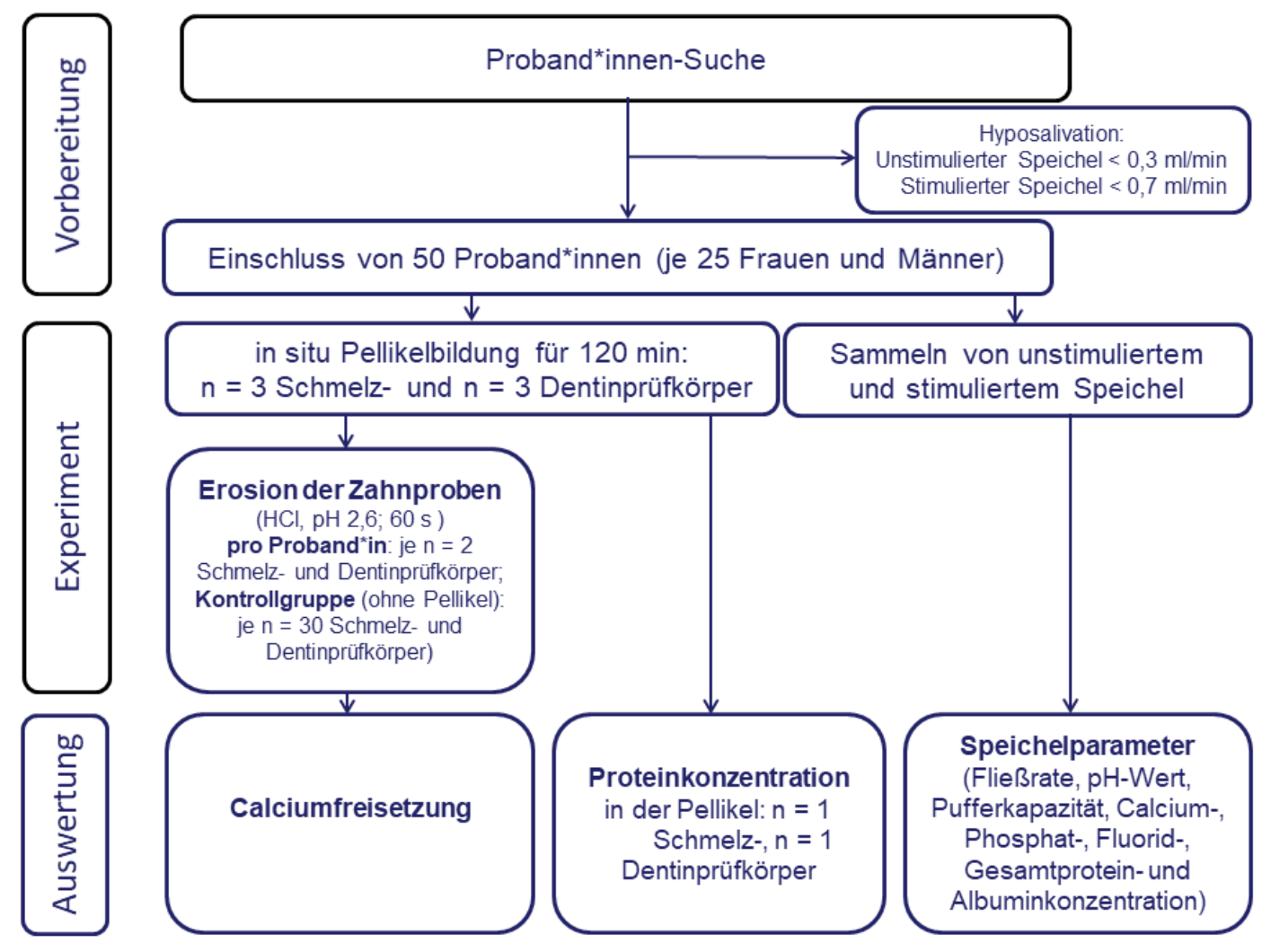

Abbildung 2.1: Versuchsablauf 


\subsection{Proband*innen}

Im Vorfeld der Studie wurde anlehnend an die Studie von Weber et al. (2015) eine Poweranalyse durchgeführt. Die Stichprobengröße lag, ausgehend von einer angenommenen Calciumfreisetzung von $10 \pm 2 \mathrm{nmol} / \mathrm{mm}^{2}$ und einem klinisch relevanten Gruppenunterschied von $20 \%$, bei $\mathrm{n}=21$ $(\alpha=0,05 ; \beta=0,9 ;$ http://clinicalc.com/stats/samplesize.aspx).

Um bei einer geschätzten Abbruchquote von $20 \%$ eine ausreichende Stichprobengröße zu erhalten, wurden insgesamt je 25 freiwillige gesunde Proband*innen im Alter zwischen 20 und 40 Jahren in die Studie einbezogen. Die Proband*innen mussten Einschlusskriterien für die Studie erfüllen (Tabelle 2.1).

Tabelle 2.1: Einschlusskriterien

\begin{tabular}{|c|l|}
\hline 1. & Alter zwischen 20 und 40 Jahren \\
\hline 2. & Nichtraucher*in \\
\hline 3. & Keine Medikamenteneinnahme (außer Kontrazeptiva) \\
\hline 4. & $\begin{array}{l}\text { Keine kieferorthopädischen Geräte, die das Tragen einer Schiene } \\
\text { unmöglich machen }\end{array}$ \\
\hline 5. & Keine Kunststoffallergie \\
\hline
\end{tabular}

Die Proband*innen wurden mindestens 24 Stunden vor Studienbeginn aufgeklärt und willigten schriftlich ein. Die Proband*innen wurden angewiesen, zwei Stunden vor Speichelabgabe nicht zu essen oder zu trinken. Nach der ersten Speichelprobenabgabe wurde sichergestellt, dass die Proband*innen eine Speichelfließrate von $\geq 0,3 \mathrm{ml} / \mathrm{min}$ (unstimuliert) bzw. $\geq 0,7 \mathrm{ml} / \mathrm{min}$ (stimuliert) aufwiesen. 


\subsection{Schmelz- und Dentinprüfkörper}

Die Schmelz- und Dentinprüfkörper wurden aus Rinderzähnen der zweiten Dentition von gesund geschlachteten Rindern des Schlachthofs Westfleisch in Paderborn gewonnen. Die Zähne wurden durch eine Sichtkontrolle auf Risse oder Unebenheiten an der Oberfläche kontrolliert und gegebenenfalls aussortiert. Bis zur weiteren Verarbeitung erfolgte die Lagerung in $\mathrm{dH}_{2} \mathrm{O}$.

Mittels eines diamantierten Hohlbohrers (Sonderanfertigung, Gebr. Brasseler, Lemgo) mit einem Innendurchmesser von 2,7 mm wurde aus den Labialflächen der Zähne Schmelz-Zylinder und aus dem Wurzelbereich Dentin-Zylinder unter Wasserkühlung herausgebohrt. Diese wurden in Kunststoff (Paladur ${ }^{\circledR}$, Kulzer, Hanau) so eingebettet, dass die Oberseite der Zylinder nicht von Kunststoff bedeckt war. Die Zahnoberfläche wurde mittels einer Schleifmaschine (RotoPol35, Struers, Cleveland, USA) und verschieden körnigem Schleifpapier von grob 800 (Hermes, Hamburg) über 1200 (Hermes, Hamburg) nach fein 4000 (Buehler, Esslingen am Neckar) unter Wasserkühlung poliert. Danach wurden die Prüfkörper mit $\mathrm{dH}_{2} \mathrm{O}$ abgespült und im Ultraschallbad (Elmasonic S, Elma Schmidbauer, Singen) für 5 min gereinigt. Des Weiteren wurden sie einer erneuten Sichtkontrolle unter dem Auflichtmikroskop (STEMI SV 11, Zeiss, Jena) mit 6,6-facher Vergrößerung unterzogen. Anschließend wurden die Prüfkörper bei der Firma BBF Sterilisationsservice (Kernen-Rommelshausen) bei 25,8 kGy gamma-sterilisiert. 


\subsection{Schienen}

In der ersten Sitzung wurde eine Unterkiefer-Abformung mit konfektionierten Unterkiefer-Löffeln (Kentzler-Kaschner Dental, Ellwangen/Jagst) und Alginat (Palgat ${ }^{\mathrm{TM}}$ Plus, 3M ESPE, Neuss) durchgeführt. Diese wurden mit handelsüblichen Desinfektionsmitteln desinfiziert und mit Superhartgips (picodent quadro-rock ${ }^{\circledR}$ plus, Dental-Produktions- \& Vertriebs- $\mathrm{GmbH}$, Wipperfürth) ausgegossen. Auf die Modelle wurden jeweils aus Gips hergestellte Prüfkörper in Regio 34 bis 36 und Regio 44 bis 46 bukkal angebracht. Die Schienen wurden aus Kunststofffolien (Erkoflex-bleach, $1 \mathrm{~mm}$, transparent, Erkodent ${ }^{\circledR}$ Erich Kopp, Pfalzgrafenweiler) hergestellt. Die überschüssigen Ränder der Schiene wurden mit einer Schere gekürzt und Öffnungen für die Exposition der Prüfkörperoberflächen mit einer Lochzange (S\&R, Gundelfingen) ausgestanzt. Anschließend wurden scharfe Kanten entfernt (Abbildungen 2.2, 2.3).

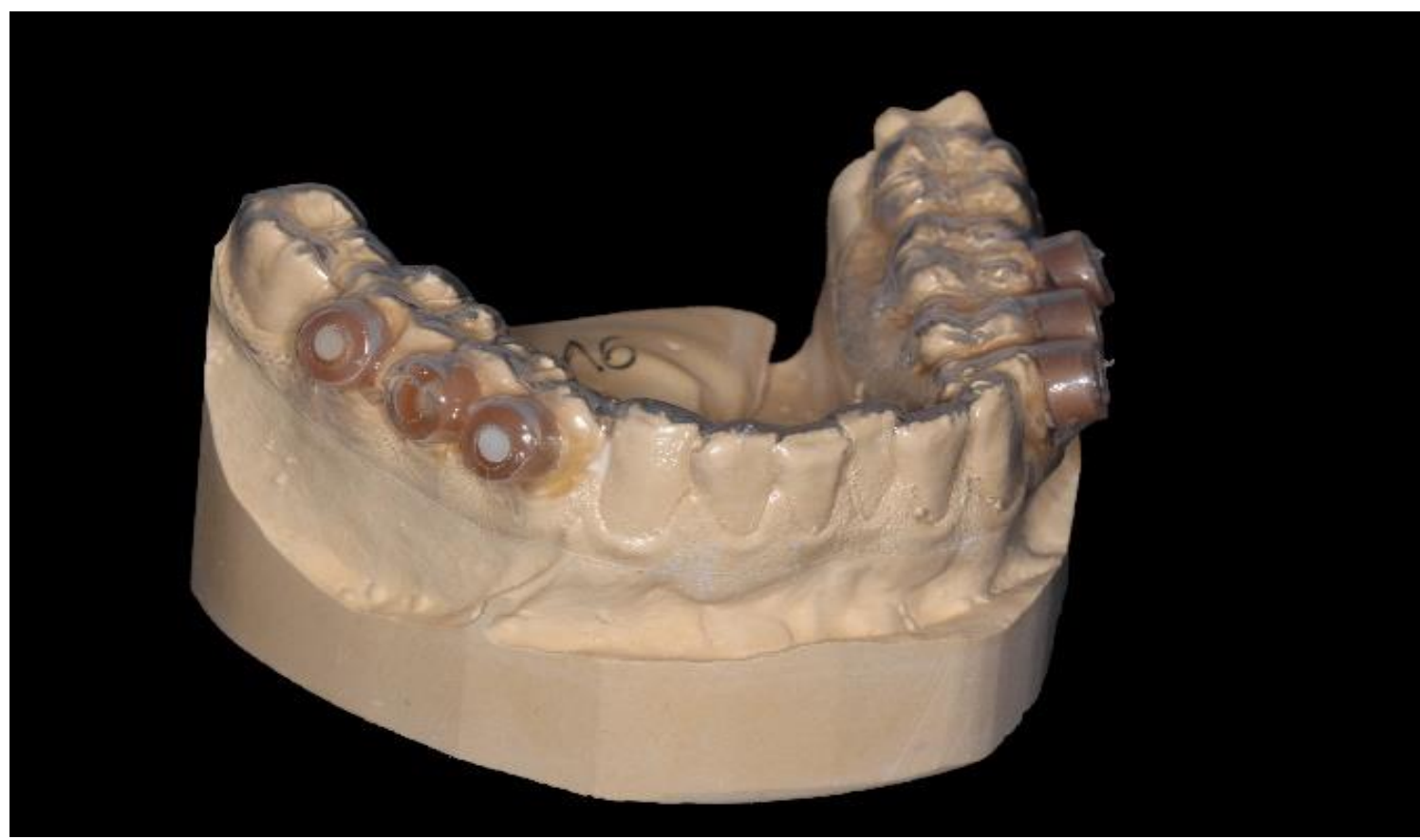

Abbildung 2.2: Modell mit Schiene und Prüfkörpern 


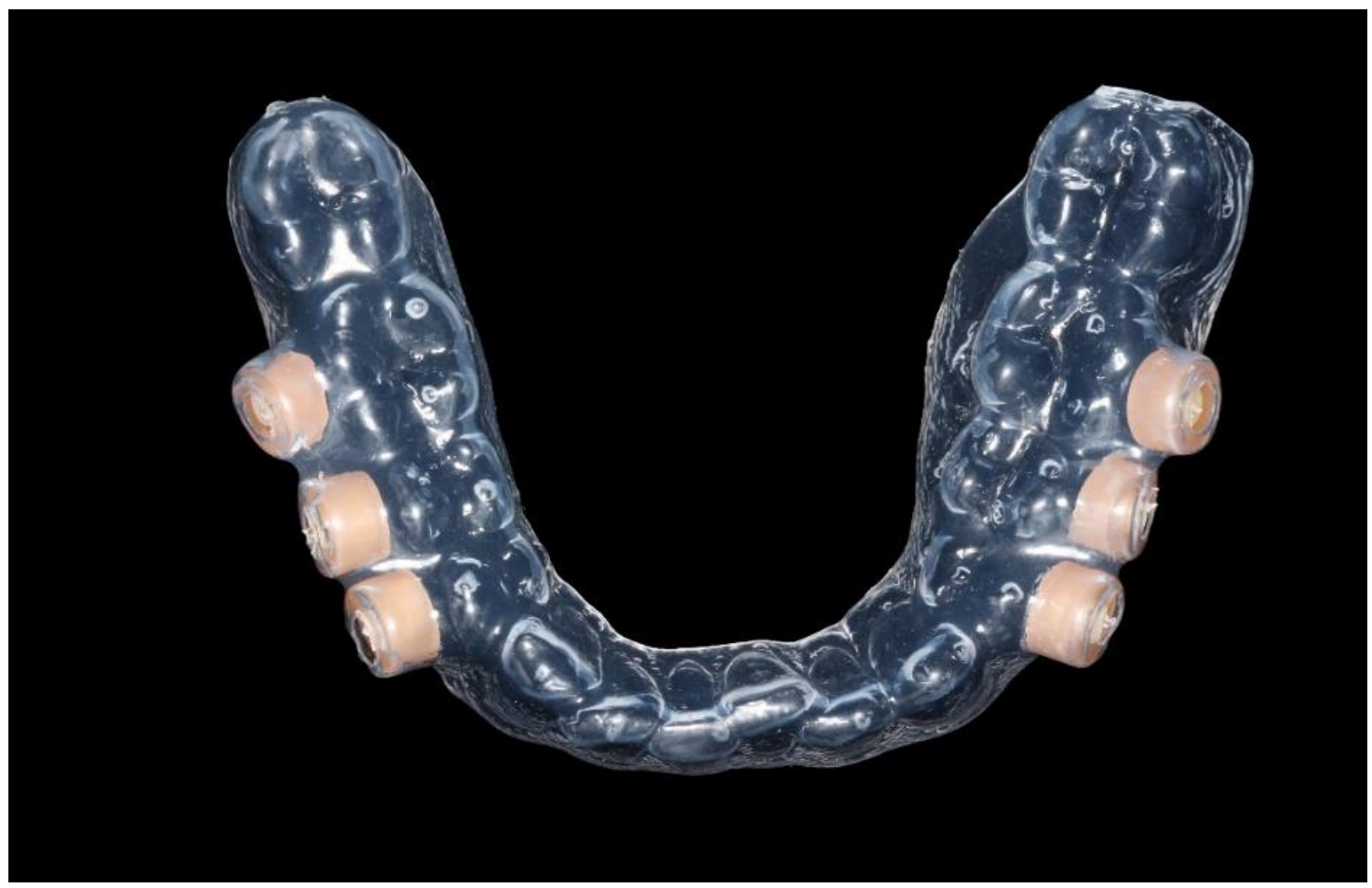

Abbildung 2.3: Schiene mit Prüfkörpern 


\subsection{Speichelparameter}

Die Speichelproben wurden an je zwei unterschiedlichen Tagen zwischen 9 Uhr und 10 Uhr gewonnen. Hierfür wurde zunächst über $5 \mathrm{~min}$ in vorab abgewogenen Speichelgefäßen (Th. Geyer, Renningen) Ruhespeichel gesammelt. Im Anschluss wurde erneut über 5 min in einem weiteren Speichelgefäß stimulierter Speichel unter Kauen eines Paraffin-Kaugummis (Saliva-Check Buffer Kit, GC Europe, Belgien) gesammelt. Die Speichelfließrate und der pH-Wert wurden unmittelbar danach bestimmt. Dann wurden die Proben bei $3000 \mathrm{U} / \mathrm{min}$ für 10 min zentrifugiert (Zentrifuge Multifuge X3R, Kulzer, Hanau) und die Pufferkapazität sowie der Calcium- und Fluoridgehalt bestimmt. Der übrige Speichel wurde in Eppendorf-Gefäße (Sarstedt, Nümbrecht) abpipettiert und bei $-21^{\circ} \mathrm{C}$ in einem Gefrierschrank (Liebherr, Ochsenhausen) eingefroren. Zur Bestimmung des Phosphat-, Gesamtprotein- und Albumingehalts wurden die Proben bei Raumtemperatur wieder aufgetaut.

\subsubsection{Speichelfließrate}

Zur Bestimmung der Speichelfließrate wurden die Probengefäße jeweils vor und nach der Speichelprobenabgabe mittels einer Präzisionswaage (Precisa 321, Precisa Gravimetrics, Dietikon, Schweiz) gewogen. Vom Messwert wurde der Leerwert subtrahiert und die Gewichtsdifferenz im Anschluss durch die Zeit der Speichelprobenabgabe $(5 \mathrm{~min})$ dividiert. Die Speicheldichte wurde mit $1 \mathrm{~g} / \mathrm{ml}$ angenommen.

\subsection{2 pH-Wert}

Zur Bestimmung des $\mathrm{pH}$-Wertes wurde ein digitales $\mathrm{pH}$-Meter $\left(\right.$ Checker $^{\circledast} \mathrm{pH}$ Tester, Hanna ${ }^{\circledR}$ instruments, Rhode Islands, USA) verwendet, das in die Speichelprobe gehalten wurde, bis ein konstantes Ergebnis angezeigt wurde. 


\subsubsection{Pufferkapazität}

Zur Bestimmung der Pufferkapazität wurde das Verfahren in Anlehnung an Ericsson angewandt (Buchgraber et al. 2013).

Hierfür wurden $750 \mu \mathrm{l}(0,005 \mathrm{M}) \mathrm{HCl}$ mit $250 \mu \mathrm{l}$ Speichel gemischt. Nach einer Inkubationszeit von 10 min bei Raumtemperatur wurde der $\mathrm{pH}$-Wert mittels einer pH-Sonde $\left(\right.$ Checker $^{\circledR} \mathrm{pH}$ Tester, Hanna ${ }^{\circledR}$ instruments, Rhode Islands, USA) gemessen.

\subsubsection{Calcium}

Die Bestimmung von Calcium wurde mit Hilfe des Fluitest CA Alll (Analyticon, Lichtenfels) durchgeführt. Der Test besteht aus einem Calcium Reagenz (R1) und einem $10 \mathrm{mg} / \mathrm{dl}$ Calcium-Standard.

Das Calcium Reagenz (R1) wurde mit einer Menge von $1000 \mu \mathrm{l}$ in die Küvetten (Sarstedt, Nümbrecht) vorgelegt. Eine dieser gefüllten Küvetten wurde zur Messung des Leerwertes (Blank) herangezogen. Zu den restlichen befüllten Küvetten wurde entweder $10 \mu \mathrm{l}$ der Standard-Lösung oder $10 \mu \mathrm{l}$ der Speichelprobe dazugegeben. Die Küvetten wurden mit Paraffin-Folie abgedeckt und der Inhalt durch Schütteln vermischt. Nach einer Inkubationszeit von 5 min wurde die Absorption bei einer Wellenlänge von $650 \mathrm{~nm}$ in einem Photometer (BioPhotometer Plus, Eppendorf, Hamburg) gemessen.

\subsubsection{Phosphat}

Zur Bestimmung des Phosphats wurde ein Phosphate Colorimetric Assay Kit (Sigma-Aldrich, St. Louis, Missouri, USA) verwendet. Das Kit besteht aus einem Phosphat Reagenz und einem 10 mM Phosphat-Standard.

Zur Herstellung der Standardreihe wurden $10 \mu \mathrm{l}$ vom $10 \mathrm{mM}$ Standard mit

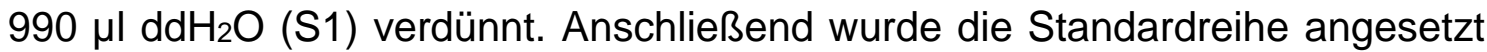
(Tabelle 2.2). 
Tabelle 2.2: Standardreihe Phosphat

\begin{tabular}{|l|l|l|}
\hline & $\mathbf{S 1}(\mu \mathrm{l})$ & $\mathrm{dd}_{2} \mathbf{O}(\mu \mathrm{l})$ \\
\hline Standard 0 (Blank) & & 200 \\
\hline Standard 1 & 10 & 190 \\
\hline Standard 2 & 20 & 180 \\
\hline Standard 3 & 30 & 170 \\
\hline Standard 4 & 40 & 160 \\
\hline Standard 5 & 50 & 150 \\
\hline
\end{tabular}

Die Speichelproben wurden zunächst mit $\mathrm{dd}_{2} \mathrm{O}$ auf $1: 5$ verdünnt. Im Anschluss wurden je $200 \mu \mathrm{l}$ der Standardreihe und der vorverdünnten Speichelproben in Doppelbestimmung in die 96-Well-Mikrotiterplatte (Sarstedt, Nümbrecht) pipettiert und danach $30 \mu \mathrm{l}$ des Phosphat Reagenz dazugegeben. Die Platte wurde mittels einer Folie abgedeckt, für $10 \mathrm{~s}$ im Varishaker-Incubator (Dynatech, Rückersdorf) vermischt und anschließend für eine Inkubationszeit von 30 min in einer lichtundurchlässigen Box gelagert. Nach Ablauf der Inkubationszeit wurde die Absorption der Proben bei einer Wellenlänge von $650 \mathrm{~nm}$ in einem Photometer (Spectra max M2, Molecular Devices, San José, Kalifornien, USA) gemessen.

\subsubsection{Fluorid}

Zur Bestimmung des Fluorids im Speichel wurden eine Fluorid-Sonde (WTW $\mathrm{pH} / \mathrm{ION}$, Xylem Analytics Germany Sales, WTW, Weilheim) und eine Fluorid

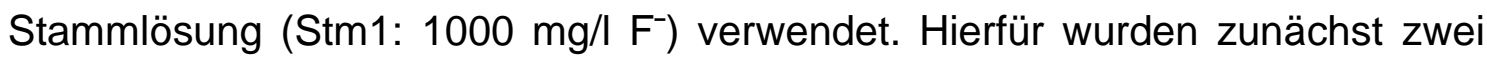
Verdünnungen aus der Stammlösung hergestellt. Die erste Verdünnung

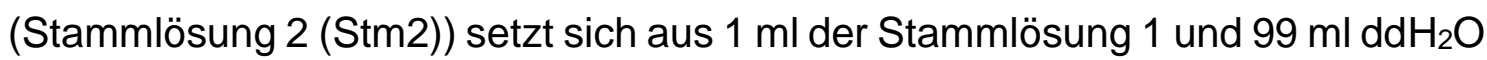
zusammen. Stammlösung 3 besteht aus $1 \mathrm{ml}$ aus der Stammlösung 2 und $99 \mathrm{ml}$ $\mathrm{ddH}_{2} \mathrm{O}$. 
Im Anschluss wurden die drei Standards zur Kalibrierung der Sonde hergestellt. Standard 1 besteht aus der Stammlösung 3. Standard 2 setzt sich aus $10 \mathrm{ml}$

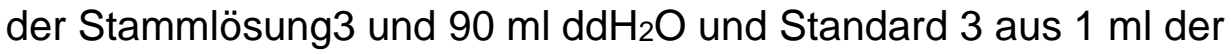

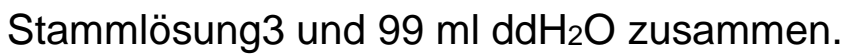

Vor jeder Verwendung wurde das Gerät mittels der drei Standards kalibriert.

$19,5 \mathrm{ml} \mathrm{ddH} \mathrm{O}_{2} \mathrm{O}$ wurde in Bechern (Th. Geyer, Renningen) vorgelegt, nach Zugabe von $0,5 \mathrm{ml}$ Speichel wurde geschüttelt und im Anschluss der Fluoridgehalt mit der lonen-Sonde gemessen.

\subsubsection{Gesamtprotein Speichel}

Gesamtprotein wurde mit Hilfe des BCA1-1KT (Sigma-Aldrich, St. Louis, Missouri, USA) gemessen. Das Versuchs-Set besteht aus einem $1 \mathrm{mg} / \mathrm{ml}$ Proteinstandard (S1) und einem Reagenz QA und QB. Zunächst wurde eine Standardreihe hergestellt (Tabelle 2.3).

Tabelle 2.3: Standardreihe Gesamtprotein Speichel

\begin{tabular}{|l|l|l|}
\hline & $\mathbf{S 1}(\boldsymbol{\mu l})$ & $\mathbf{d d H}_{2} \mathbf{O}(\boldsymbol{\mu l})$ \\
\hline Standard 0 (Blank) & & 250 \\
\hline Standard 1 & 50 & 200 \\
\hline Standard 2 & 100 & 150 \\
\hline Standard 3 & 150 & 100 \\
\hline Standard 4 & 200 & 50 \\
\hline Standard 5 & 250 & \\
\hline
\end{tabular}

Zur Herstellung des BCA-Working-Reagenz wurden $21 \mathrm{ml}$ Reagenz QA mit 0,42 ml Reagenz QB gemischt. Die 96-Well-Platte (Sarstedt, Nümbrecht) wurde mit je $25 \mu \mathrm{l}$ Standard oder unverdünntem Speichel und $200 \mu \mathrm{l}$ BCA Working- 
Reagenz befüllt, mit einer Folie abgedeckt, im Varishaker-Incubator (Dynatech, Rückersdorf) für $10 \mathrm{~s}$ gemischt und anschließend für $15 \mathrm{~min}$ bei $60^{\circ} \mathrm{C}$ inkubiert. Nach Ablauf der Inkubationszeit wurde die Absorption der Proben bei einer Wellenlänge von $562 \mathrm{~nm}$ in einem Photometer (Spectra max M2, Molecular Devices, San José, Kalifornien, USA) gemessen.

\subsubsection{Albumin}

Zur Bestimmung des Albumins in den Speichelproben wurde das Kit ORG 5MA Micro-Albumin (ORGENTEC Diagnostika, Mainz) verwendet. Das Set besteht aus einer gebrauchsfertigen Mikrotiterplatte, sechs gebrauchsfertigen Standards von A-F, je einer Positiv- und Negativkontrolle, Probenpuffer PA, Enzymkonjugat, TMB Substrat, Stopplösung und Waschpuffer. Zunächst wurden $5 \mathrm{ml}$

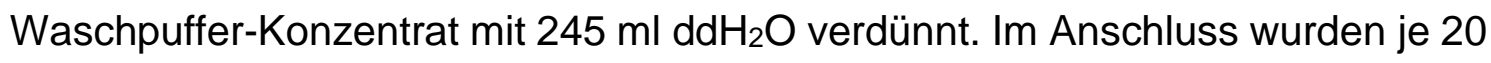
$\mu$ Standard oder Probe in die Kavitäten der Mikrotiterplatte pipettiert und je 100 $\mu l$ Enzymkonjugat hinzugefügt. Nach einer Inkubationszeit von $30 \mathrm{~min}$ bei Raumtemperatur wurden die Kavitäten entleert und dreimal mit je $300 \mu \mathrm{l}$ Waschpuffer gewaschen. Dann wurde je Kavität $100 \mu \mathrm{l}$ TMB Substratlösung hinzugegeben. Nach einer Inkubationszeit von $15 \mathrm{~min}$ bei Raumtemperatur wurde jeweils $100 \mu \mathrm{l}$ Stopplösung dazu pipettiert. Die optische Dichte konnte nach weiteren 5 min Inkubationszeit bei Raumtemperatur mit einer Wellenlänge von $450 \mathrm{~nm}$ im Photometer (Spectra max M2, Molecular Devices, San José, Kalifornien, USA) bestimmt werden. 


\subsection{Bestimmung der durch Erosion freigesetzten Calcium- Ionen}

Die 120 min getragenen Schmelz- und Dentinkörper wurden für $10 \mathrm{~s}$ mit destilliertem Wasser abgespült. Direkt im Anschluss wurden je zwei Schmelzund Dentinprüfkörper für je $60 \mathrm{~s}$ in $1 \mathrm{ml}$ Salzsäure $(\mathrm{pH}$-Wert 2,6; $\mathrm{c}=0,0025 \mathrm{~mol} / \mathrm{l})$ in ein $2 \mathrm{ml}$ Eppendorf-Gefäß gegeben und dabei manuell 60-mal pro Minute horizontal geschwenkt. Nach Ablauf der Zeit wurden die Prüfkörper aus der Säure entfernt. Die Proben wurden bis zur Bestimmung der durch Erosion freigesetzten Calcium-lonen im Kühlschrank (Liebherr, Ochsenhausen) gelagert. Für die Kontrollgruppe wurden je 30 ungetragene pellikelfreie Schmelz- und Dentinprüfkörper erodiert. Der pH-Wert der Säure wurde täglich vor Versuchsdurchführung mittels der pH-Sonde $\left(H_{a n n a}{ }^{\circledR}\right.$ instruments, Rhode Islands, USA) überprüft.

Die Bestimmung der Calciumfreisetzung erfolgte mit Hilfe des Fluitest CA Alll (Analyticon, Lichtenfels). Der Test besteht aus einem Calcium Reagenz (R1) und einem Calcium Standard (10 mg/dl).

Zunächst wurde eine Standardreihe (Tabelle 2.4) hergestellt, dazu wurde der Calcium Standard (10 mg/dl) 1:10 mit dd $\mathrm{H}_{2} \mathrm{O}$ verdünnt (S1).

Tabelle 2.4: Standardreihe Calcium bei Erosion

\begin{tabular}{|l|l|l|}
\hline & Standard $(\boldsymbol{\mu l})$ & $\mathbf{d d H}_{2} \mathbf{O}(\mu \mathrm{l})$ \\
\hline Standard 1 (St1) & $100 \mathrm{S1}$ & 900 \\
\hline Standard 2 (St2) & $200 \mathrm{St1}$ & 200 \\
\hline Standard 3 (St3) & $200 \mathrm{St} 2$ & 200 \\
\hline Standard 4 (St4) & $200 \mathrm{St} 3$ & 200 \\
\hline Standard 5 (St5) & $200 \mathrm{St} 4$ & 200 \\
\hline Standard 6 (St6) & $200 \mathrm{St5}$ & 200 \\
\hline
\end{tabular}


Die Kavitäten der 96-Well-Platte (Sarstedt, Nümbrecht) wurden mit $10 \mu \mathrm{l}$ Standard 1 bis 6 bzw. Probe und $100 \mu$ Reagenz R1 befüllt. Nach einer Inkubationszeit von 5 min bei Raumtemperatur wurde die Absorption bei einer Wellenlänge von $650 \mathrm{~nm}$ im Photometer (Spectra max M2, Molecular Devices, San José, Kalifornien, USA) gemessen.

\subsection{Gesamtprotein in der Pellikel}

Zur Bestimmung des Gesamtproteingehalts in der Pellikel wurden je ein für 120 min intraoral getragener Schmelz- und Dentinprüfkörper mit 2 ml dd ${ }_{2} \mathrm{O}$ in Eppendorf-Gefäßen für $5 \mathrm{~min}$ bei Raumtemperatur in ein Ultraschallbad (Elmasonic S, Elma Schmidbauer, Singen) gegeben, um ein Lösen der Pellikel hervorzurufen. Anschließend wurden die Prüfkörper wieder entnommen und die Proben bei $-21^{\circ} \mathrm{C}$ eingefroren. Nach dem Auftauen und manuellem Schwenken der Proben wurde der Gesamtproteingehalt in der Pellikel bestimmt.

Der Protein Nachweis in der Pellikel wurde mit dem QuantiPro ${ }^{\mathrm{TM}}$ BCA Assay Kit (Sigma-Aldrich, St. Louis, Missouri, USA) durchgeführt. Das Kit besteht aus einem QuantiPro Puffer QA, zwei Reagenzien QB und QC und einem ProteinStandard.

Zunächst wurde der mitgelieferte Protein-Standard im Verhältnis von 1:20 verdünnt, sodass ein Proteinstandard (S1) mit einer Konzentration von 50 $\mathrm{g} / \mathrm{ml}$ entstand. Damit wurde eine Standardreihe hergestellt (Tabelle 2.5). 
Tabelle 2.5: Standardreihe Gesamtprotein Pellikel

\begin{tabular}{|l|l|l|}
\hline & $\mathbf{S 1}(\mu \mathrm{l})$ & $\mathbf{d d H}_{2} \mathbf{O}(\mu \mathrm{l})$ \\
\hline Standard 0 (Blank) & & 1000 \\
\hline Standard 1 & 10 & 990 \\
\hline Standard 2 & 100 & 900 \\
\hline Standard 3 & 200 & 800 \\
\hline Standard 4 & 400 & 600 \\
\hline Standard 5 & 600 & 400 \\
\hline
\end{tabular}

Zur Herstellung des QuantiPro-Working-Reagenz wurde je 7,25 ml QA und QB mit 0,29 ml QC gemischt. Die Kavitäten der 96-Well-Platte (Sarstedt, Nümbrecht) wurden mit je $150 \mu \mathrm{l}$ Standard oder Probe und $150 \mu \mathrm{l}$ QuantiPro-WorkingReagenz befüllt. Nach einer Inkubationszeit von 60 min bei $60{ }^{\circ} \mathrm{C}$ wurde die Absorption bei einer Wellenlänge von $562 \mathrm{~nm}$ im Photometer (Spectra max M2, Molecular Devices, San José, Kalifornien, USA) bestimmt. 


\subsection{Statistische Auswertung}

Die Calciumfreisetzung wurde separat für Schmelz und Dentin jeweils mittels einfaktorieller Varianzanalyse und paarweisen t-Tests, korrigiert nach BonferroniHolm, analysiert. Die in der Pellikel gemessene Proteinkonzentration und die einzelnen Speichelparameter wurden mit t-Tests, korrigiert nach BonferroniHolm, verglichen. Mögliche Zusammenhänge der Speichelparameter mit der Calciumfreisetzung aus den erodierten Schmelz- und Dentinprüfkörpern sowie dem Proteingehalt in der Pellikel wurden mit Pearson-Korrelationen analysiert. Die multiple lineare Regression wurde angewandt, um zu überprüfen, ob es Zusammenhänge zwischen Geschlecht und Proteinkonzentration in der Pellikel und der säureinduzierten Calciumfreisetzung aus den Schmelz- und Dentinprüfkörpern gibt.

Die statistische Auswertung wurde mit der Statistik Software R (Version 3.5.1, www.r-project.org) durchgeführt und das Signifikanzniveau auf $\alpha=0,05$ festgelegt. 


\section{$3 \quad$ Ergebnisse}

In die Studie wurden insgesamt 50 Proband ${ }^{*}$ innen eingeschlossen, davon waren 25 weiblich und 25 männlich. Das Durchschnittsalter der Studienteilnehmerinnen lag bei 25,8 $\pm 3,6$ Jahren und das der Studienteilnehmer bei 26,7 \pm 4,0 Jahren.

\subsection{Speichelparameter}

Im stimulierten Speichel zeigten sich keine signifikanten geschlechtsspezifischen Unterschiede (Tabelle 3.1). Im unstimulierten Speichel wiesen der pH-Wert ( $p=$ $0,048)$ und die Gesamtproteinkonzentration $(p=0,026)$ einen signifikanten Unterschied zwischen den Geschlechtern auf (Tabelle 4.1). Frauen (pH-Wert: 7,0 $\pm 0,2$ ) hatten einen niedrigeren $\mathrm{pH}$-Wert als Männer ( $\mathrm{pH}$-Wert: 7,2 $\pm 0,2$ ). Die Gesamtproteinkonzentration war bei Frauen (Gesamtprotein: 954,4 \pm 324,3 $\mu \mathrm{g} / \mathrm{ml}$ ) im Vergleich zu männlichen Teilnehmern (Gesamtprotein: 1313,7 $\pm 606,0$ $\mu \mathrm{g} / \mathrm{ml})$ niedriger. 
Tabelle 3.1: Speichelparameter (Mittelwert \pm Standardabweichung) in stimulierten und unstimulierten Speichelproben aller Studienteilnehmer*innen

\begin{tabular}{|c|c|c|c|c|}
\hline & \multicolumn{2}{|c|}{ Unstimulierter Speichel } & \multicolumn{2}{|c|}{ Stimulierter Speichel } \\
\hline & Männer & Frauen & Männer & Frauen \\
\hline $\begin{array}{l}\text { Fließrate } \\
\text { (ml/min) }\end{array}$ & $0,9 \pm 0,4$ & $0,8 \pm 0,4$ & $2,0 \pm 1,1$ & $1,8 \pm 0,7$ \\
\hline $\mathrm{pH}$ & $7,2 \pm 0,2^{*}$ & $7,0 \pm 0,2^{\star}$ & $7,5 \pm 0,2$ & $7,4 \pm 0,2$ \\
\hline $\begin{array}{l}\text { Puffer- } \\
\text { kapazität }\end{array}$ & $4,1 \pm 0,5$ & $3,9 \pm 0,7$ & $4,6 \pm 0,6$ & $4,4 \pm 0,7$ \\
\hline $\begin{array}{l}\text { Gesamtpro- } \\
\text { tein ( } \mu \mathrm{g} / \mathrm{ml})\end{array}$ & $1313,7 \pm 606,0^{*}$ & $954,4 \pm 324,3^{*}$ & $718,9 \pm 231,8$ & $678,7 \pm 145,7$ \\
\hline $\begin{array}{l}\text { Albumin } \\
(\mu \mathrm{g} / \mathrm{ml})\end{array}$ & $253,6 \pm 225,0$ & $165,2 \pm 116,7$ & $79,5 \pm 75,3$ & $59,8 \pm 39,1$ \\
\hline $\begin{array}{l}\text { Calcium } \\
\text { (mmol/l) }\end{array}$ & $1,4 \pm 0,3$ & $1,4 \pm 0,3$ & $1,1 \pm 0,3$ & $1,1 \pm 0,2$ \\
\hline $\begin{array}{l}\text { Phosphat } \\
\text { (mmol/l) }\end{array}$ & $5,0 \pm 1,4$ & $5,1 \pm 1,4$ & $3,5 \pm 0,7$ & $3,8 \pm 1,2$ \\
\hline $\begin{array}{l}\text { Fluorid } \\
\text { ( } \mu \mathrm{mol} / \mathrm{l})\end{array}$ & $4,6 \pm 2,3$ & $3,4 \pm 1,8$ & $6,0 \pm 2,0$ & $5,2 \pm 1,7$ \\
\hline
\end{tabular}

Die mit * markierten Parameter wiesen signifikante Unterschiede zwischen männlichen und weiblichen Studienteilnehmer*innen auf. 


\subsection{Calciumfreisetzung aus erodierten Schmelz- und Dentinprüfkörpern}

Die Kontrollgruppe wies eine Calciumfreisetzung von 13,2 $\pm 3,7 \mathrm{nmol} / \mathrm{mm}^{2}$ (Schmelz) bzw. 11,9 $\pm 3,3 \mathrm{nmol} / \mathrm{mm}^{2}$ (Dentin) auf.

Die intraoral getragenen Prüfkörper zeigten im Vergleich zur Kontrollgruppe sowohl bei den Schmelz- $(p=0,004$; Abbildung 3.1) als auch bei den Dentinprüfkörpern ( $p=0,017$; Abbildung 3.2) eine signifikant reduzierte Calciumfreisetzung.

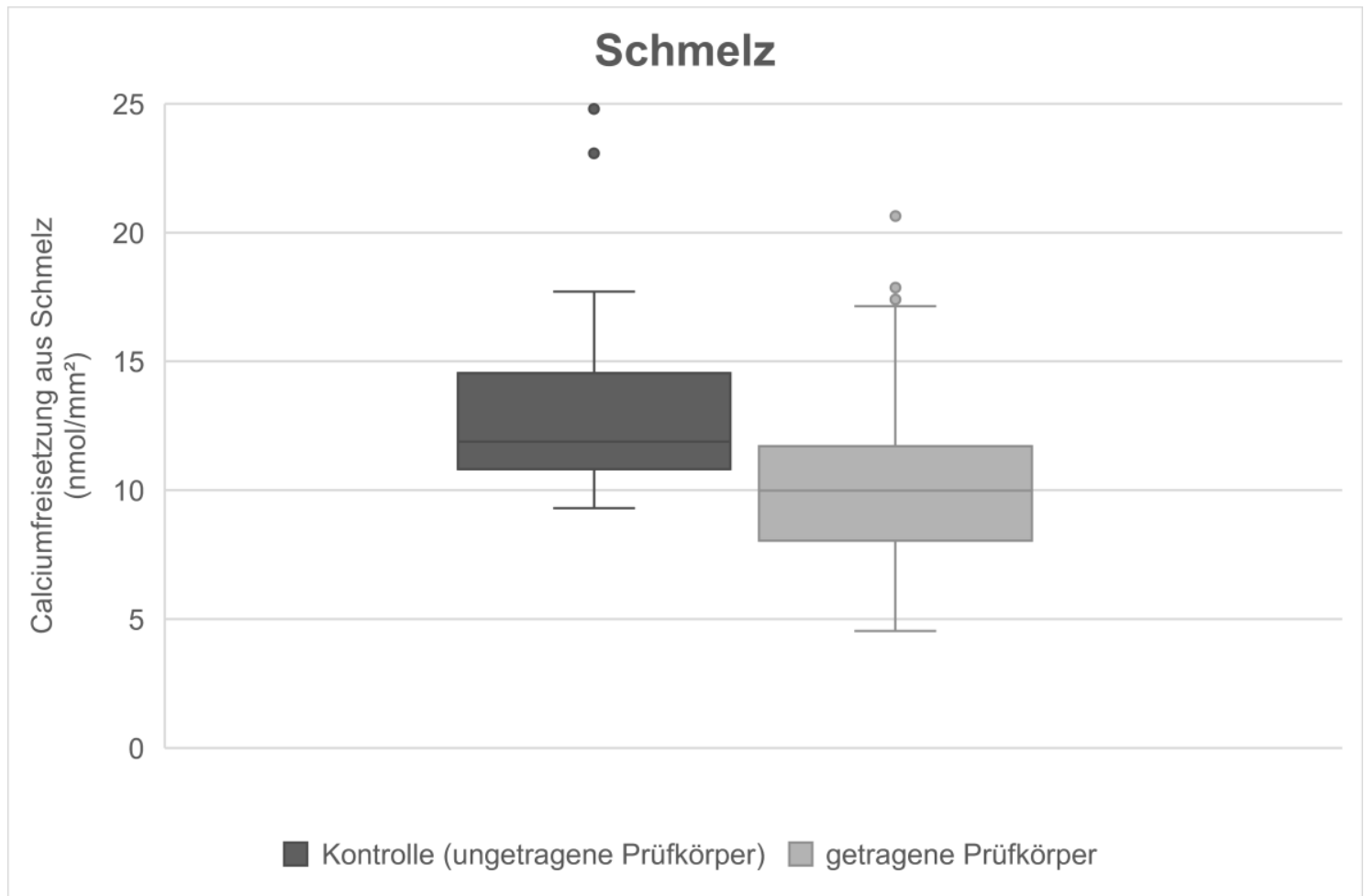

Abbildung 3.1: Säureinduzierte Calciumfreisetzung aus Schmelz von getragenen Prüfkörpern im Vergleich zur Kontrolle. Die Boxen repräsentieren die Interquartil-Spanne (IQR) zwischen dem 1. und 3. Quartil sowie den Medianwert. Die Whisker befinden sich jeweils zwischen den äußersten Datenpunkten im 1. Quartil - 1,5 (IQR) und dem 3. Quartil + 1,5 (IQR). Ausreißer (<Q1 - 1,5 (IQR) oder > Q3 + 1,5 (IQR)) sind mit einem Punkt markiert. 


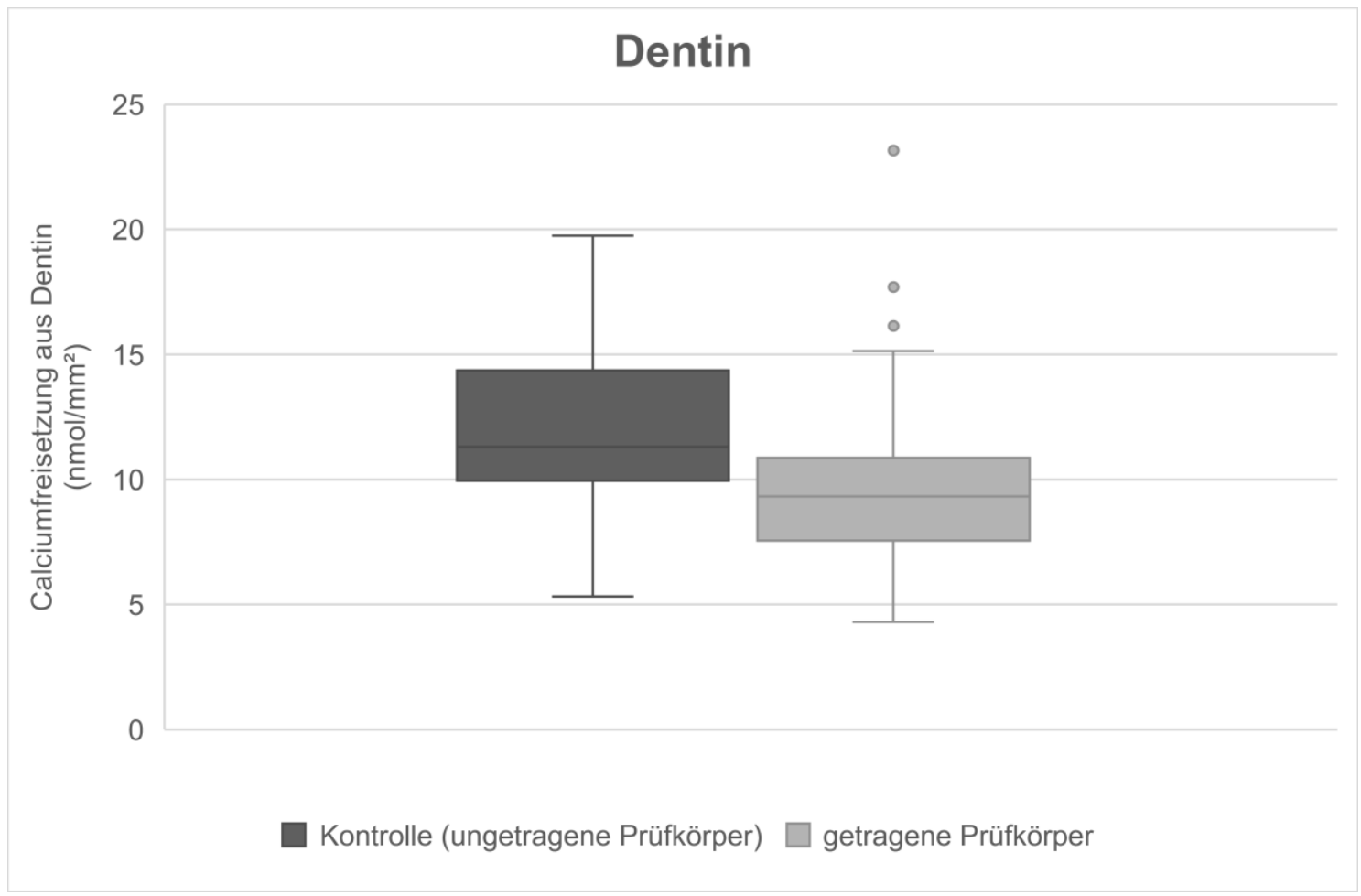

Abbildung 3.2: Säureinduzierte Calciumfreisetzung aus Dentin von getragenen Prüfkörpern im Vergleich zur Kontrolle. Die Boxen repräsentieren die Interquartil-Spanne (IQR) zwischen dem 1. und 3. Quartil sowie den Medianwert. Die Whisker befinden sich jeweils zwischen den äußersten Datenpunkten im 1. Quartil - 1,5 (IQR) und dem 3. Quartil + 1,5 (IQR). Ausreißer (<Q1 - 1,5 (IQR) oder > Q3 + 1,5 (IQR)) sind mit einem Punkt markiert.

Im Vergleich zur Kontrollgruppe zeigten sowohl die von weiblichen als auch die von männlichen Proband*innen getragenen Prüfkörper im Schmelz eine signifikante Reduktion der Calciumfreisetzung (Frauen: $p=0,049$; Männer: $p=0,007$; Abbildung 3.3). Jedoch war bei den Dentinprüfkörpern nur bei den Frauen eine signifikante Reduktion der Calciumfreisetzung gegenüber der Kontrollgruppe zu beobachten ( $p=0,049$; Abbildung 3.4). Bei den von Probanden getragenen Dentinprüfkörpern war der protektive Effekt der Pellikel auf den Dentinoberflächen nicht signifikant ( $p=0,211$; Abbildung 3.4).

Die Calciumfreisetzung reduzierte sich bei den mit Speichel benetzten Schmelzprüfkörpern im Vergleich zur Kontrollgruppe bei den Frauen um $17,4 \pm 28,1 \%$ und bei den Männern um 24,0 $\pm 27,5 \%$. Die Calciumfreisetzung reduzierte sich bei den mit Speichel benetzten Dentinprüfkörpern bei den Frauen 
um 19,3 $\pm 24,0 \%$ und bei den Männern um 12,9 $\pm 34,9 \%$ gegenüber der Kontrollgruppe.

Die von Proband*innen getragenen Prüfkörper zeigten im Vergleich zwischen den Geschlechtern keinen signifikanten Unterschied hinsichtlich der Calciumfreisetzung (Schmelz: $p=0,402$; Abbildung 3.3; Dentin: $p=0,440$; Abbildung 3.4).

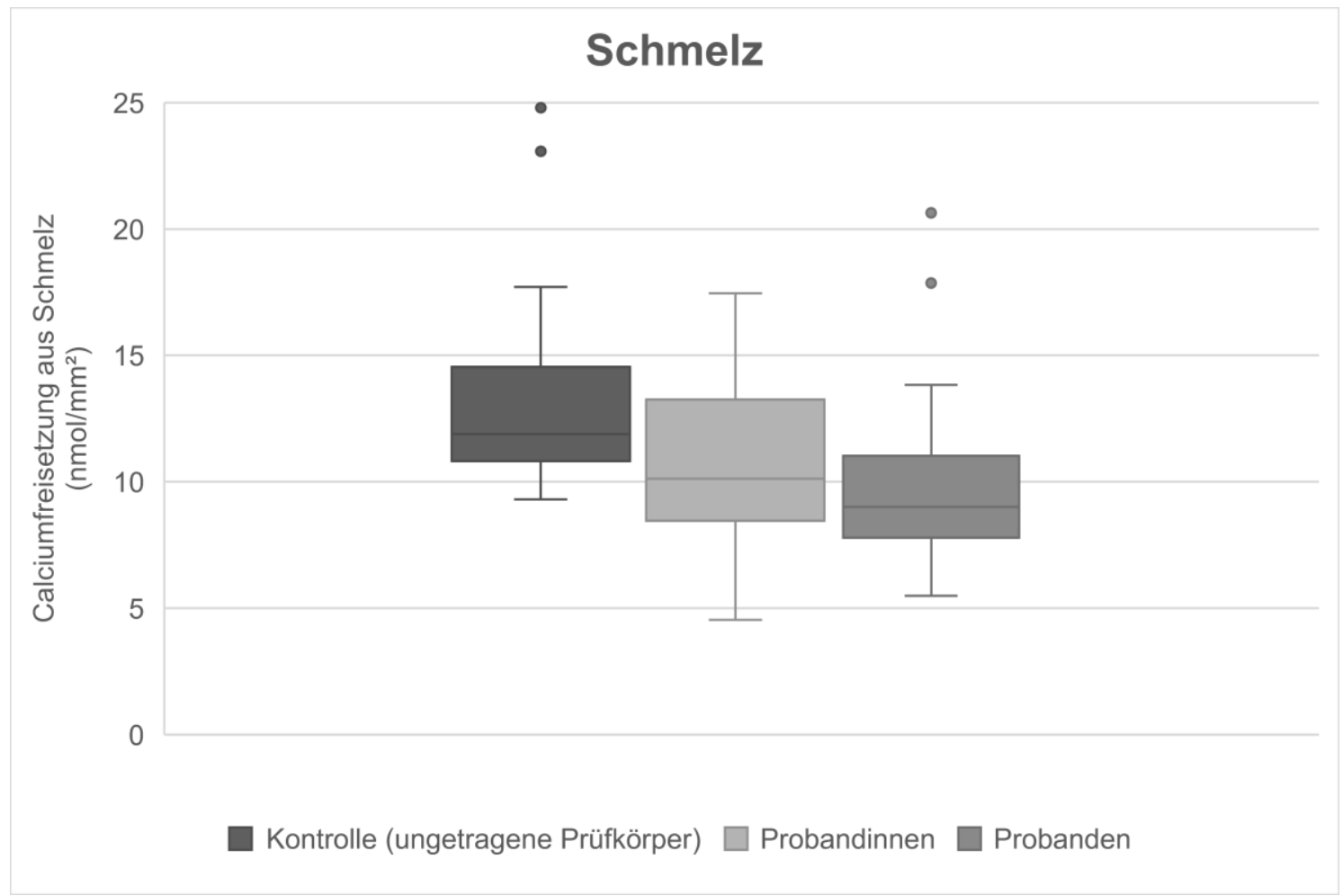

Abbildung 3.3: Säureinduzierte Calciumfreisetzung aus Schmelz. Die Boxen repräsentieren die Interquartil-Spanne (IQR) zwischen dem 1. und 3. Quartil sowie den Medianwert. Die Whisker befinden sich jeweils zwischen den äußersten Datenpunkten im 1. Quartil - 1,5 (IQR) und dem 3. Quartil + 1,5 (IQR). Ausreißer (<Q1 - 1,5 (IQR) oder $>\mathrm{Q} 3+1,5(\mathrm{IQR}))$ sind mit einem Punkt markiert. 


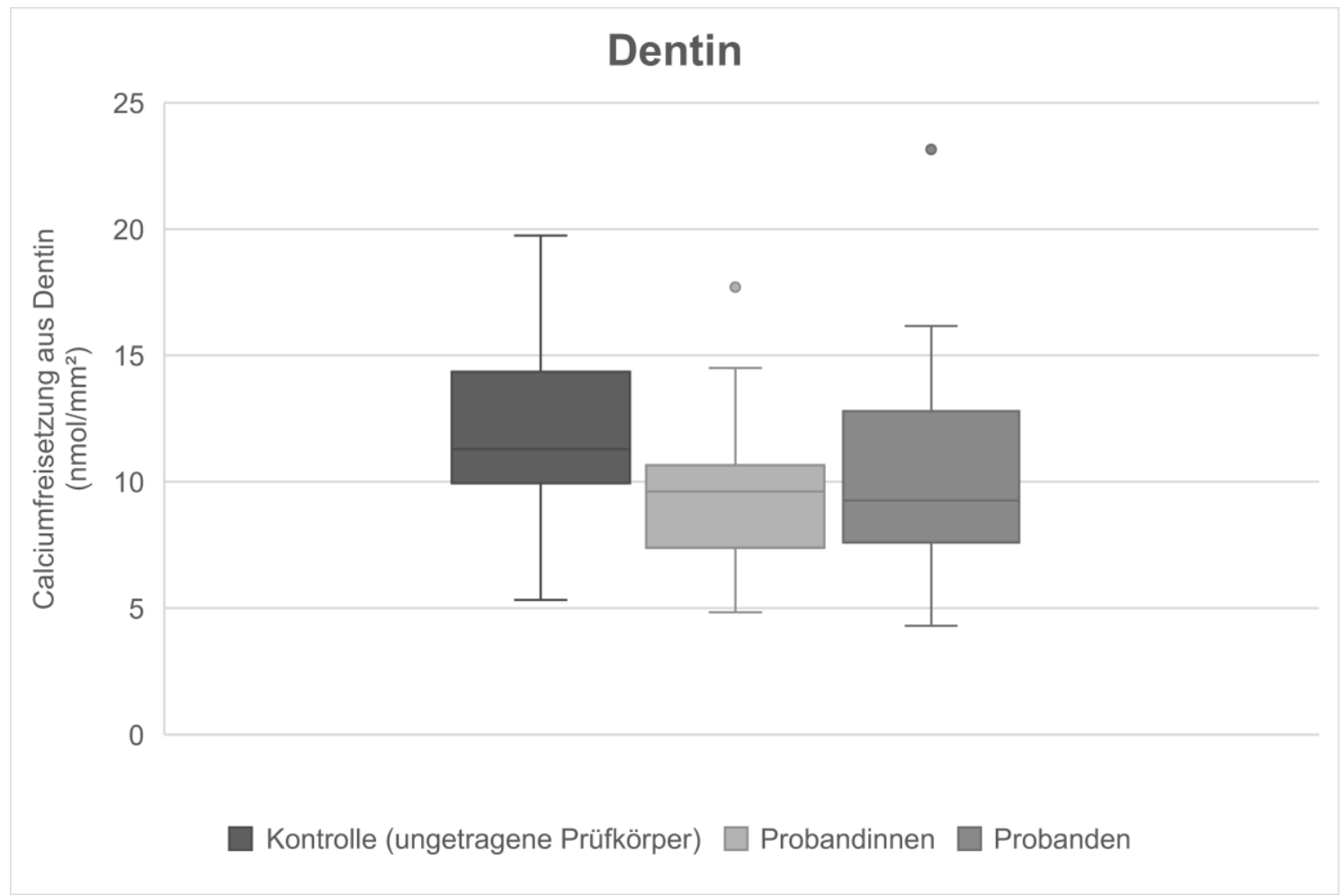

Abbildung 3.4: Säureinduzierte Calciumfreisetzung aus Dentin. Die Boxen repräsentieren die Interquartil-Spanne (IQR) zwischen dem 1. und 3. Quartil sowie den Medianwert. Die Whisker befinden sich jeweils zwischen den äußersten Datenpunkten im 1. Quartil - 1,5 (IQR) und dem 3. Quartil + 1,5 (IQR). Ausreißer (<Q1 - 1,5 (IQR) oder $>\mathrm{Q} 3+1,5(\mathrm{IQR}))$ sind mit einem Punkt markiert. 


\subsection{Proteinkonzentration der Pellikel}

Die Proteinkonzentration der Pellikel zeigte zwischen Frauen (Schmelz: 158,2 \pm $88,3 \mathrm{ng} / \mathrm{mm}^{2}$, Dentin: $144,9 \pm 115,0 \mathrm{ng} / \mathrm{mm}^{2}$ ) und Männern (Schmelz: 127,8 \pm $84,8 \mathrm{ng} / \mathrm{mm}^{2}$, Dentin: $126,0 \pm 111,0 \mathrm{ng} / \mathrm{mm}^{2}$ ) keinen signifikanten Unterschied (Schmelz: $p=0,438$; Abbildung 3.5, Dentin: $p=0,571$; Abbildung 3.6).

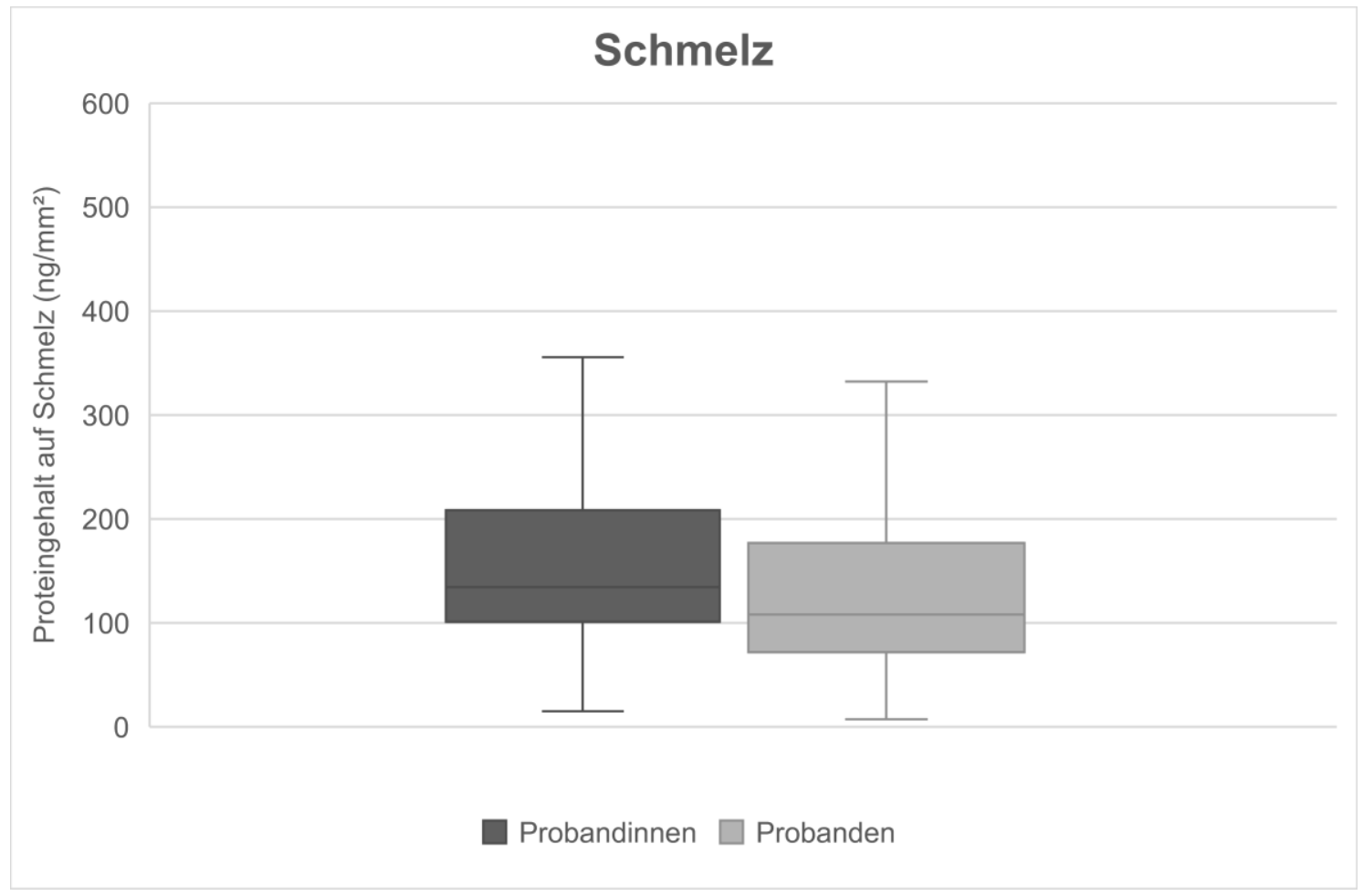

Abbildung 3.5: Proteingehalt der Pellikel auf Schmelz. Die Boxen repräsentieren die Interquartil-Spanne (IQR) zwischen dem 1. und 3. Quartil sowie den Medianwert. Die Whisker befinden sich jeweils zwischen den äußersten Datenpunkten im 1. Quartil - 1,5 (IQR) und dem 3. Quartil + 1,5 (IQR). 


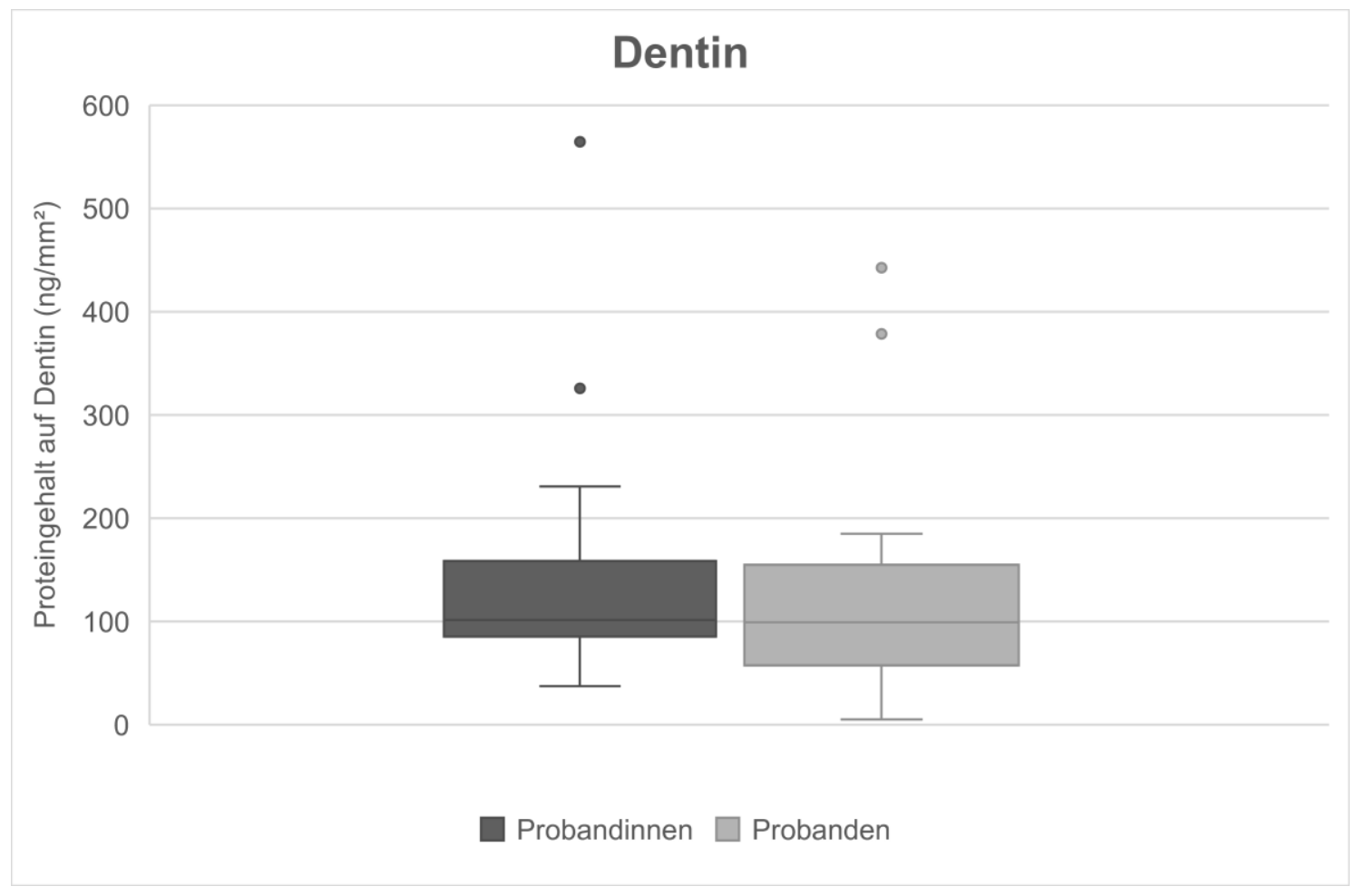

Abbildung 3.6: Proteingehalt der Pellikel auf Dentin. Die Boxen repräsentieren die Interquartil-Spanne (IQR) zwischen dem 1. und 3. Quartil sowie den Medianwert. Die Whisker befinden sich jeweils zwischen den äußersten Datenpunkten im 1. Quartil - 1,5 (IQR) und dem 3. Quartil + 1,5 (IQR). Ausreißer (<Q1 - 1,5 (IQR) oder > Q3 + 1,5 (IQR)) sind mit einem Punkt markiert. 


\subsection{Einfluss der Speichelparameter auf die}

\section{Calciumfreisetzung}

Keiner der untersuchten Speichelparameter hatte einen Einfluss auf die Calciumfreisetzung aus den erodierten Schmelz- und Dentinprüfkörpern (Tabelle 3.2).

Tabelle 3.2: Einfluss der Speichelparameter auf die Calciumfreisetzung ( $p$-Werte der Pearson-Korrelationen)

\begin{tabular}{|l|l|l|l|l|}
\hline \multirow{2}{*}{} & \multicolumn{2}{|l|}{ Unstimulierter Speichel } & \multicolumn{2}{l|}{ Stimulierter Speichel } \\
\cline { 2 - 5 } & $\begin{array}{l}\text { Ca- } \\
\text { Freisetzung } \\
\text { Schmelz }\end{array}$ & $\begin{array}{l}\text { Ca- } \\
\text { Freisetzung } \\
\text { Dentin }\end{array}$ & $\begin{array}{l}\text { Ca- } \\
\text { Freisetzung } \\
\text { Schmelz }\end{array}$ & $\begin{array}{l}\text { Ca- } \\
\text { Freisetzung } \\
\text { Dentin }\end{array}$ \\
\hline Fließrate & 1 & 1 & 1 & 1 \\
\hline pH & 0,95 & 1 & 1 & 1 \\
\hline Pufferkapazität & 0,48 & 1 & 1 & 1 \\
\hline $\begin{array}{l}\text { Gesamtprotein- } \\
\text { gehalt }\end{array}$ & 1 & 1 & 1 & 1 \\
\hline Albumin & 1 & 1 & 1 & 1 \\
\hline Calcium & 1 & 1 & 1 & 0,76 \\
\hline Phosphat & 1 & 1 & 0,36 & 1 \\
\hline Fluorid & 1 & 1 & 1 & 1 \\
\hline
\end{tabular}




\subsection{Einfluss des Proteingehalts in der Pellikel auf die Calciumfreisetzung}

Die Pearson-Korrelation, adjustiert nach Bonferroni-Holm, zeigte keine linearen Abhängigkeiten zwischen der Calciumfreisetzung und dem Proteingehalt in der Pellikel (Schmelz: $p=0,917$; Dentin: $p=0,106$ ).

Auch in der multiplen linearen Regression war die Calciumfreisetzung aus den Schmelz- und Dentinprüfkörpern unabhängig vom Geschlecht und dem Proteingehalt auf den Prüfkörpern (Schmelz: $\Delta R^{2}=0,049, F=1,508, p=0,207$; Dentin: $\Delta R^{2}=0,008, F=1,083, p=0,383$ ). 


\section{Diskussion}

\subsection{Material und Methoden}

Bei der vorliegenden Studie handelt es sich um eine In-situ-Studie. Dieses Versuchsmodell zur Bestimmung protektiver Effekte einer in situ gebildeten Pellikel auf Erosionen wurde in zahlreichen Studien bereits angewandt (Hannig et al. 2007; Wiegand et al. 2008a; Jager et al. 2011; Hannig et al. 2012; Weber et al. 2015).

\subsubsection{Prüfkörper}

Es wurden bovine Prüfkörper verwendet. Ein großer Vorteil hierbei liegt darin, dass Rinderzähne in größeren Mengen zur Verfügung stehen als menschliche Zähne. Bovine Schmelz- und Dentinprüfkörper wurden schon in vorangegangenen In-situ-Studien zur Bestimmung erosiver Effekte verwendet (Hannig et al. 2003; Hara et al. 2006; Hannig et al. 2007; Wiegand et al. 2008a). In der Studie von Falla-Sotelo et al. (2005) zeigte der Mineralgehalt des menschlichen Zahnes sowohl im Schmelz wie auch im Dentin im Vergleich zu Rinderzähnen keinen signifikanten Unterschied. Die Mikrohärte von bovinem und humanem Schmelz ist nicht unterschiedlich, das menschliche Wurzeldentin hat im Vergleich zum bovinen Dentin jedoch eine höhere Mikrohärte (Turssi et al. 2010).

Hinsichtlich der Reaktion auf Erosion und Abrasion verhalten sich humane und bovine Zahnhartsubstanzen allerdings ähnlich. Wegehaupt et al. (2008) konnten für den Zahnhartsubstanzverlust durch Erosion und Abrasion keine signifikanten Unterschiede zwischen humanem und bovinem Dentin feststellen. In der Studie von Attin et al. (2007) gab es keinen signifikanten Unterschied im Schmelzverlust von bovinem und humanem Schmelz in Bezug auf Abrasionen. Es zeigte sich jedoch ein größerer Schmelzverlust bei bovinen Zähnen im Vergleich zu humanen Zähnen nach Erosion bzw. Erosion-Abrasion.

Die Oberfläche der Prüfkörper wurde vorab poliert. Ob es Unterschiede in der Pellikelanhaftung an natürlichen oder polierten Schmelz- und Dentinoberflächen 
gibt, muss noch in weiteren Studien untersucht werden. In einigen Studien konnte jedoch gezeigt werden, dass an rauen Oberflächen im Vergleich zu glatten Oberflächen mehr Proteine adsorbiert werden (Carlén et al. 2001; Müller et al. 2006). Auch Hannig und Hannig (2009) kamen in ihrer Studie zu dem Ergebnis, dass die Proteinabsorption von der Rauigkeit der Oberfläche abhängig ist. Ebenfalls wurde in einer In-vivo-Studie an erodierten Zahnoberflächen eine unterschiedliche Proteinzusammensetzung im Vergleich zur unbehandelten Schmelzoberflächenstruktur gezeigt (Mutahar et al. 2017).

In anderen Studien wurde außerdem gezeigt, dass eine natürliche Zahnoberfläche im Gegensatz zu einer polierten Zahnoberfläche einen signifikant geringeren Zahnhartsubstanzverlust und eine höhere Oberflächenhärte nach einem erosiven Angriff aufweist (Ganss et al. 2000; Lin et al. 2017). Durch die Politur wurden in dieser Studie eventuell vorhandene Entkalkungen oder oberflächliche Veränderungen beseitigt und eine einheitliche Oberflächenstruktur erzeugt. Es muss jedoch bedacht werden, dass dies unter Umständen zu einer verminderten Proteinabsorption an den Prüfkörpern geführt haben kann und somit das Ausmaß der säureinduzierten Calciumfreisetzung beeinflusst wurde.

In der vorliegenden Studie wurde der eingebettete Prüfkörper auf der gesamten Oberfläche mit Speichel benetzt. Die Bestimmung des Gesamtproteingehalts wurde daher in einer Pellikel bestimmt, die zuvor auf Schmelz und Kunststoff bzw. Dentin und Kunststoff gebildet worden war. In früheren Studien konnte gezeigt werden, dass es große Ähnlichkeiten bezüglich des Proteinadsorptionsverhaltens auf unterschiedlichen Werkstoffen gibt (Hannig 1997; Hannig 1999a; Hannig et al. 2004a). Trotzdem kann nicht ausgeschlossen werden, dass in der vorliegenden Studie eine unterschiedliche Proteinabsorption an Zahnoberfläche und Kunststoff stattgefunden hat. 


\subsubsection{Speichelgewinnung}

Um den zirkadianen Rhythmus der Speichelbildung (Dawes 1974; Edgar 1990) zu berücksichtigen, wurde die Speichelprobe an beiden Versuchstagen zwischen 9 Uhr und 10 Uhr entnommen. Zur Stimulation wurde handelsübliches ParaffinKau-Wachs verwendet. Da ein verminderter Speichelfluss das Ausmaß erosiver Zahnhartsubstanzverluste begünstigt (Rytömaa et al. 1998; Jensdottir et al. 2013; Zwier et al. 2013), wurden nur Proband*innen mit einer Fließrate von mindestens $0,3 \mathrm{ml} / \mathrm{min}$ und für stimulierten Speichel von mindestens $0,7 \mathrm{ml} / \mathrm{min}$ in die Studie eingeschlossen. Die Fließrate des Speichels beeinflusst den Gehalt an organischen Substanzen wie z. B. Proteine und anorganischen Substanzen unter anderem Calcium, Fluorid und Phosphat, die die initialen Säureangriffe auf die Zahnoberfläche inhibieren oder minimieren (van Nieuw Amerongen et al. 2004; Hara et al. 2006; Hara und Zero 2014).

\subsubsection{Pellikel}

Wie schon in mehreren Studien gezeigt wurde, vermindert die Pellikel das Ausmaß dentaler Erosionen, bietet jedoch keinen vollständigen Schutz (Meurman und Frank 1991; Hannig et al. 2003; Hara et al. 2006; Hannig et al. 2009; Cheaib und Lussi 2011). Einige Studien kommen zu dem Ergebnis, dass die Pellikelbildungszeit den Erosionsschutz einer Pellikel nicht beeinflusst (Meurman und Frank 1991; Hannig und Balz 1999; Hannig et al. 2003). In vorangegangenen Studien wurden hierfür unterschiedliche Pellikelbildungszeiten untersucht. Schon nach einer Pellikelbildungszeit von 3 min konnte ein antierosiver Effekt gezeigt werden (Hannig et al. 2004b). In einer weiteren Studie von Hannig et al. (2003) wurden die protektiven Eigenschaften der in situ gebildeten Pellikel nach einer Bildungszeit von 2, 6, 12 und 24 Stunden untersucht. Dabei zeigten sich keine signifikanten Unterschiede zwischen den unterschiedlichen Bildungszeiten und dem Ausmaß des erosiven Prozesses.

Lee et al. (2013) entdeckten jedoch zu unterschiedlichen Pellikelbildungszeiten (5, 10, 60 und $120 \mathrm{~min}$ ) verschiedene Proteine in der Pellikel, sodass die Pellikelbildungszeit die Erosionsprotektivität einer Pellikel möglicherweise doch beeinflusst. In der frühen Pellikel nach einer Bildungszeit von 5 bis 10 min fanden 
sich mehr Proteine, die eine hohe Affinität zu Calcium und Phosphat aufwiesen, in der später gebildeten Pellikel (zwischen 10 und 120 min Bildungszeit) überwogen Proteine, die zur Protein-Protein-Interaktion fähig sind (Lee et al. 2013).

In der vorliegenden Arbeit wurden die Prüfkörper für 120 min im Unterkiefer mittels einer Schiene getragen. Bei einer Tragedauer von 120 min sollte in Bezug auf die Studie von Lee et al. (2013) die Pellikel überwiegend Proteine, die zur Protein-Protein-Interaktion fähig sind, enthalten. Dies müsste in einer weiteren Studie untersucht werden.

Mehrere Studien zeigten eine unterschiedliche Zusammensetzung des Speichels zwischen verschiedenen oralen Expositionsorten (Dawes et al. 1989; Veerman et al. 1996). Die Pellikel variiert je nach Bildungsort in Aufbau, Dicke und Zusammensetzung (Hannig und Joiner 2006). In mehreren Studien wurde eine dickere Pellikelbildung bukkal im Oberkiefer im Vergleich zu palatinal beobachtet (Amaechi et al. 1999; Hannig 1999b; Hannig et al. 2003). Die Studie von Amaechi et al. (1999) zeigte eine dickere Pellikelschicht bukkal im Oberkiefer als palatinal. Die bukkale Pellikel bot einen größeren erosiven Schutz als die dünnere palatinale Pellikel. Hannig et al. (2004) zeigten jedoch, dass der Erosionsschutz der Pellikel bukkal nicht größer als palatinal ist. Die dünnere initial gebildete Basalschicht weist eine erosionsprotektive Wirkung auf (Hannig und Balz 1999). Die dickere bukkale Pellikelschicht weist eine erhöhte Säurelöslichkeit im Vergleich zur dünneren elektronendichten Schicht auf (Hannig et al. 2004b; Vitkov et al. 2004; Hannig und Joiner 2006; Hannig et al. 2009).

Auch Hannig und Balz (2001) zeigten in ihrer Studie, dass der Pellikelbildungsort keinen Einfluss auf die Schutzfunktion einer Pellikel hat, die über 24 Stunden gebildet wurde. Vielmehr scheint die dünne initiale elektronendichte basale Membran die protektive Wirkung vor Erosionen auszumachen. Dieses Ergebnis wird in einer weiteren Studie von Hannig et al. (2009) belegt. Sie untersuchten mittels TEM eine in situ 120 Minuten-Pellikel unter Einfluss von säurehaltigen Getränken. Die TEM-Aufnahmen zeigten strukturelle Veränderungen in der äußeren globulären Pellikelschicht. Des Weiteren konnten eine kontinuierliche basale Membran bzw. Pellikelüberreste auf der Schmelzoberfläche beobachtet werden. 
In der vorliegenden Arbeit wurde lediglich der Gesamtproteingehalt der Pellikel bestimmt. Eine differenzierte Proteomanalyse wurde nicht durchgeführt. Lee et al. (2013) fanden in ihrer Studie eine signifikante quantitative und qualitative Veränderung der Proteinzusammensetzung der Pellikel innerhalb der ersten 120 min. In der 5- und 10-Minuten-Pellikel befanden sich eine größere Menge an Proteinen, die Verbindungen zu Calcium oder Phosphat eingehen können. In der 60- und 120-Minuten-Pellikel fanden sich mehrheitlich Proteine, die eine ProteinProtein-Interaktion eingehen können (Lee et al. 2013). Auch da Silva Ventura et al. (2017) konnten in ihrer In-vivo-Studie Proteinvariationen in der Pellikel bezüglich ihres Expositionsortes im Zahnbogen feststellen. Sie untersuchten die nach 120 min gebildete Pellikel von 9 Proband*innen an 6 verschiedenen Lokalisationsorten. Insgesamt wurden 363 unterschiedliche Proteine in der Pellikel entdeckt, wovon 25 Proteine in allen Regionen zu finden waren, unter anderem Lysozym C, Laktoferrin, Statherin, IgA 2, Myeloperoxidase und prolinreiches Protein 3. Hämoglobin trat vermehrt in der Pellikel palatinal und bukkal im hinteren Teil des Zahnbogens auf, wohingegen Calpain-8 nur palatinal im hinteren Teil der Oberkieferzahnreihe angesiedelt war. Cystatin war lediglich in der vorderen Region aufzufinden.

\subsubsection{Calciumfreisetzung}

Für die Erosion wurden die Prüfkörper in der vorliegenden Studie anlehnend an das Studienprotokoll von Wiegand et al. (2008b) für $60 \mathrm{~s}$ in $1 \mathrm{ml}$ Salzsäure mit einem $\mathrm{pH}$-Wert von 2,6 und einer Konzentration von $0,0025 \mathrm{~mol} / \mathrm{l}$ inkubiert. Nach Wiegand et al. (2008b) zeigte sich bei einem konstanten pH-Wert von 2,6 für Salzsäure, Zitronensäure und Phosphorsäure kein unterschiedlicher Effekt auf pellikelbedeckte Schmelz- und Dentinprüfkörper. Salzsäure eignet sich gut zur Bestimmung dentaler Erosionen mittels Calciumfreisetzung, da sie in Wasser vollständig in Protonen und Chlorid-Ionen dissoziiert. Andere Säuren, wie Oxalsäure, Weinsäure und Zitronensäure, bilden Chelat-Komplexe mit Calcium, so dass sich bei diesen Säuren die Arsenazo III Methode nicht zur Calciumbestimmung eignet (Attin et al. 2005; Hannig et al. 2005b; Attin 2006). 
Mehrere Studien verwendeten unterschiedliche Säureinkubationszeiten von $60 \mathrm{~s}$ (Hannig et al. 2004b; Wiegand et al. 2008a), 5 bis 30 min (Nekrashevych und Stösser 2003; Hara et al. 2006; Wetton et al. 2007; Wiegand et al. 2008b) und 120 min (Meurman und Frank 1991) zur Analyse der protektiven Eigenschaften einer Pellikel gegenüber erosiven Prozessen. Das Ausmaß der erosiven Wirkung einer Säure hängt von der Einwirkdauer und vom pH-Wert ab (West et al. 2001; Hannig et al. 2005b). Um einen natürlichen Erosionsprozess in der Mundhöhle nachzuahmen, z. B. den Konsum eines säurehaltigen Getränks oder das Erbrechen, wurde in der Studie eine Säureinkubationszeit von $60 \mathrm{~s}$ gewählt.

\subsubsection{Bestimmung von Erosionen}

Erosive Prozesse können mit unterschiedlichen Methoden untersucht werden. Hierfür eignen sich zum einen verschiedene physikalische Methoden, wie die Mikrohärtebestimmung (Barbour und Rees 2004), die Oberflächenprofilometrie (Schlueter et al. 2005), die Mikroradiographie (Herkströter et al. 1991; Schlueter et al. 2010) und die TEM (Attin 2006). Auf der anderen Seite werden chemische Verfahren wie die Atomabsorptionsspektroskopie (Willis 1961; Trudeau und Freier 1967; Wiegand et al. 2008a), die photometrische Bestimmung in Lösung gegangener lonen (Attin et al. 2005; Hannig et al. 2005b) oder der Gebrauch einer lonen-sensitiven Elektrode (Hara und Zero 2008) angewandt.

In der vorliegenden Studie wurde zur Bestimmung erosiver Effekte die photometrische Arsenazo III Methode (Smith und Bauer 1979) angewandt, da sie sich für die quantitative Untersuchung kleinster Mengen an gelösten CalciumIonen gut eignet (Attin et al. 2005; Hannig et al. 2005b; Hannig et al. 2008; Ganss et al. 2009). Nach Attin et al. (2005) kann mit dieser Methode bereits ein Schmelzverlust von $1,6 \mathrm{~nm}$ bei einem Probendurchmesser von $2 \mathrm{~mm}$ nachgewiesen werden. Auch nach einer sehr kurzen Erosionszeit von $5 \mathrm{~s}$ konnten bereits in Lösung gegangene Calcium-Ionen mit dieser Methode gemessen werden (Hannig et al. 2008). Des Weiteren sind nur geringe Testvolumina nötig, um erodierte Calcium-Ionen zu detektieren (Attin et al. 2005). 
Dieses Verfahren ist außerdem zur Erfassung der Erosionskinetik aufgrund des geringen Messvolumenverbrauchs geeignet (Hannig et al. 2005b). Vorteile der photometrischen Calcium-Messung sind auch die kostengünstige, einfache und schnelle Versuchsdurchführung, da auch unbehandelte Proben verwendet werden können, was ein aufwändiges Schleifen und Polieren der Proben erspart (Attin 2006). Dieses Verfahren liefert jedoch keine direkten Informationen über den Zahnhartsubstanzverlust der Prüfkörperoberfläche (Schlueter et al. 2011).

\subsection{Ergebnisse}

\subsubsection{Speichel}

In der Analyse der Speichelparameter zeigte sich, dass der pH-Wert im unstimulierten Speichel bei Frauen niedriger war als bei Männern. Auch der Gesamtproteingehalt war im unstimulierten Speichel bei Frauen niedriger als bei Männern. In Studien von Prodan et al. (2015) und Li-Hui et al. (2016) konnten ebenfalls ein erniedrigter pH-Wert (Prodan et al. 2015; Li-Hui et al. 2016) und eine erniedrigte Proteinkonzentration (Prodan et al. 2015) bei Frauen im Vergleich zu den Männern gezeigt werden. Des Weiteren fanden sie allerdings auch geschlechtsspezifische Unterschiede bezüglich der Fließrate (Li-Hui et al. 2016) und der Pufferkapazität (Prodan et al. 2015).

Jager et al. (2011) belegten in ihrer Studie, dass die antierosive Wirkung der Pellikel im unstimulierten Speichel signifikant von Speichelparametern wie Albumingehalt, Fließrate des Speichels, Gesamtproteingehalt, Harnstoff- und Natriumkonzentration sowie dem pH-Wert abhängig ist. Im stimulierten Speichel ist die Abhängigkeit von Harnstoff, Natrium und Phosphat belegt. Im Hinblick auf die Fließrate, die Pufferkapazität, den pH-Wert, die Gesamtproteinkonzentration und Konzentration von Mineralien im Speichel wiesen die Ergebnisse dieser Arbeit ähnliche Werte wie in der von Jager et al. (2011) durchgeführten Studie auf. In der vorliegenden Arbeit haben die geschlechtsspezifischen Unterschiede im unstimulierten Speichel jedoch keinen Einfluss auf die Calciumfreisetzung der erodierten Schmelz- und Dentinprüfkörper und den Proteingehalt der gebildeten 
Pellikel. Diese Unterschiede können zum Teil auf unterschiedliche methodische Aspekte zurückgeführt werden: In der Studie von Jager et al. (2011) wurde statt Schmelz reines Hydroxylapatit verwendet, die Pellikelbildungszeit auf $90 \mathrm{~min}$ begrenzt und Zitronensäure ( $\mathrm{pH}$-Wert 3 ) als Inkubationsmedium verwendet. Außerdem wurde die Calciumfreisetzung mittels Atomabsorptionsspektrometrie bestimmt.

Die Mineralkonzentration des Speichels und vor allem das Verhältnis zwischen Speichelproteinen und Speichelionen spielt eine wichtige Rolle für das Ausmaß der Erosionsprotektivität der Pellikel. Baumann et al. (2016) untersuchten in ihrer Studie die Zusammensetzungen des Speichels in Bezug auf die erosionsschützende Wirkung der gebildeten Pellikel auf Zahnschmelz. Hierfür verwendeten sie vier unterschiedliche Speichelvariationen: 1.natürlicher Speichel, 2.künstlich hergestellter Speichel nur mit Ionen angereichert, 3.natürlicher Speichel, dialysiert gegen künstlichen Speichel, mit Proteinen und lonen angereichert und 4.natürlicher Speichel, dialysiert gegen deionisiertes Wasser, mit Proteinen angereichert. Sie kamen zu dem Ergebnis, dass die Pellikel, die von proteinreichem Speichel ohne lonen gebildet wird, den effektivsten Erosionsschutz für die Schmelzoberfläche darstellt. In einer weiteren Studie analysierten Baumann et al. (2017) den Effekt von verschiedenen Calciumkonzentrationen im Speichel auf die erosionsschützende Wirkung der gebildeten Pellikel. Natürlicher, aber mit unterschiedlichen Calciumkonzentrationen angereicherter, Speichel zeigte signifikant eine größere „Erweichung“ der Schmelzoberfläche im Vergleich zu natürlichem Speichel sowie künstlich hergestelltem Speichel mit verschiedenen Calciumkonzentrationen. Es gab jedoch keinen signifikanten Unterschied bezüglich des Calciumverlustes zwischen natürlichem und künstlichem Speichel und den jeweils unterschiedlichen Calciumkonzentrationen (Baumann et al. 2017).

Insgesamt hatten sowohl Proteine als auch lonen eine positive Wirkung auf den Erosionsschutz der gebildeten Pellikel. Das Ausmaß der Protektivität der Pellikel in Anwesenheit von sowohl Proteinen als auch lonen im Speichel hängt jedoch stark von ihrer jeweiligen Konzentration ab (Baumann et al. 2016; Baumann et al. 2017). In der hier vorliegenden Studie wurde kein signifikanter geschlechtsspezifischer Unterschied in der Calcium-, Fluorid- oder Phosphatkonzentration 
von unstimuliertem und stimuliertem Speichel entdeckt. Allerdings wurde ein signifikanter geschlechtsspezifischer Unterschied in der Gesamtproteinkonzentration im unstimulierten Speichel gefunden, dieser wirkte sich jedoch nicht auf den Erosionsschutz der gebildeten Pellikel aus.

In der vorliegenden Studie wurden nur der Gesamtprotein- und Albumingehalt im Speichel bestimmt. Lediglich die Gesamtproteinkonzentration im unstimulierten Speichel zeigte einen signifikanten Unterschied zwischen den Geschlechtern. In einigen aktuellen Studien wurden weitere geschlechtsspezifische Unterschiede hinsichtlich der Proteinzusammensetzung des Speichels gefunden (Srivastava et al. 2008; Murr et al. 2017; Xiao et al. 2017).

Murr et al. (2017), die in ihrer Studie den Einfluss von Alter, Geschlecht, BodyMass-Index (BMI), Rauchen und Bildung in Bezug auf die Proteinmerkmale im stimulierten Speichel von 187 Proband*innen untersuchten, kamen zu dem Resultat, dass 27 Proteine signifikant vom Geschlecht abhängig sind. Bei der Analyse des Proteoms von Xiao et al. (2017) wurden im unstimulierten Speichel 82 genderspezifische Proteine analysiert.

In der vorliegenden Studie wurde keine spezifische Untersuchung der Proteinmerkmale im Speichel durchgeführt. Möglicherweise hätte es jedoch weitere geschlechtsspezifische Speichelproteinmerkmale gegeben, die wiederum einen Einfluss auf das Ausmaß säureinduzierter Calciumfreisetzung gehabt hätten. Dies könnte ein Ziel für eine weiterführende Untersuchung sein.

\subsubsection{Pellikel}

In der vorliegenden Studie zeigten die von weiblichen und männlichen Probanden getragenen Schmelz- und Dentinprüfkörper eine signifikante Reduktion der Calciumfreisetzung gegenüber den Kontrollgruppen bei einem Säureangriff. Das Vorhandensein einer Pellikel auf Schmelz- oder Dentinoberflächen reduzierte das Ausmaß dentaler Erosionen, wie in der Literatur beschrieben (Meurman und Frank 1991; Hannig et al. 2003; Hara et al. 2006; Wiegand et al. 2008a; Hannig et al. 2009). Es wurde jedoch keine erhöhte Schutzwirkung für Schmelz gegenüber Dentin festgestellt, wie es in den Studien von Wetton et al. (2006) und Wiegand et al. (2008b) der Fall war. 
Bislang belegte die Literatur, dass einige Proteine die Demineralisation der Zahnoberfläche durch Abpufferung der Protonen verlangsamen (Hannig und Hannig 2014). Carpenter et al. (2014) zeigten mit ihrer Studie, dass einige Proteine möglicherweise die Erosionsprotektivität der Pellikel beeinflussen. Sie verglichen in ihrer Studie die Zusammensetzung der Schmelzpellikel von Patient*innen mit erosiven Zahnhartsubstanzverlusten mit einer gesunden Kontrollgruppe. Das Protein Statherin wurde insgesamt $35 \%$ weniger in der Pellikel von Patient*innen mit erosiven Zahnhartsubstanzdefekten im Vergleich zur Kontrollgruppe gefunden. Die Calciumkonzentration in der Pellikel war bei Patient*innen mit erosiven Zahnhartsubstanzdefekten im Vergleich zur Kontrollgruppe um $50 \%$ niedriger.

Mutahar et al. (2017) untersuchten in ihrer Studie die Gesamtproteinkonzentration sowie die Konzentration von Muzin 5b, Albumin, Statherin und Carboanhydrase VI in der Pellikel, die von erodierten und nicht erodierten Zahnflächen von Proband*innen mit erosiven Zahnhartsubstanzdefekten entnommen wurden. Sie stellten eine signifikant niedrigere Gesamtproteinkonzentration sowie weniger Statherin an erodierten Zahnoberflächen verglichen mit gesunden Zahnoberflächen im selben Proband*in fest.

Des Weiteren konnten Muzin (Delecrode et al. 2015a), Histatin (Siqueira et al. 2010), Casein-Muzin (Cheaib und Lussi 2011) und Cystatin-B (Delecrode et al. 2015b) antierosive Eigenschaften zugesprochen werden. Allerdings wurde in der hier vorliegenden Studie nur der Gesamtproteingehalt in der Pellikel bestimmt. Es konnte jedoch kein Unterschied zwischen Frauen und Männern in Bezug auf den Gesamtproteingehalt festgestellt werden.

In Hinblick auf eine detaillierte Proteinanalyse der Speichelpellikel ist noch nicht bekannt, ob es geschlechtsspezifische Unterschiede, wie sie schon in der Proteinanalyse des Speichels gefunden wurden, gibt. Möglicherweise könnte eine Proteinanalyse der Pellikel Aufschluss über eine differenzierte Zusammensetzung der Pellikel und somit auch geschlechtsspezifische Hinweise auf die Protektivität einer Pellikel vor Säureangriffen geben. 


\subsubsection{Schlussfolgerungen}

Die geschlechtsspezifischen Unterschiede im unstimulierten Speichel haben keinen Einfluss auf die Calciumfreisetzung der erodierten Schmelz- und Dentinprüfkörper und die Zusammensetzung der gebildeten Pellikel, obwohl die Proteinkonzentration und der $\mathrm{pH}$-Wert von unstimuliertem Speichel bei Frauen niedriger waren als bei Männern. Die Nullhypothese, dass die säureinduzierte Calciumfreisetzung aus pellikelbedeckten Schmelz- und Dentinprüfkörpern keine signifikanten geschlechtsspezifischen Unterschiede aufweist, wurde somit bestätigt.

In weiteren Studien sollten mögliche geschlechtsspezifische Unterschiede der Proteinzusammensetzung in der Pellikel und im Speichel in Bezug auf die Entstehung säureinduzierter Zahnhartsubstanzdefekte untersucht werden. 


\section{$5 \quad$ Zusammenfassung}

Ziel dieser In-situ-Studie war es zu untersuchen, ob es einen geschlechtsspezifischen Unterschied in der Speichel- und/oder Pellikelzusammensetzung gibt und ob dieser einen Einfluss auf die Erosion von mit Pellikel beschichteten Schmelz- und Dentinprüfkörpern hat.

Bovine Schmelz- und Dentinprüfkörper (je $n=3$ ) wurden von freiwilligen gesunden Proband*innen (je $n=25$; Frauen: 25,8 \pm 3,5 Jahre, Männer: 26,7 \pm 4,0 Jahre) für $120 \mathrm{~min}$ in einer Unterkieferschiene zur Bildung einer Pellikel getragen. Im Anschluss wurden je zwei Schmelz- und Dentinprüfkörper und die Kontrollgruppe (ohne Speichelkontakt, je $n=30$ ) für $60 \mathrm{~s}$ in Salzsäure ( $\mathrm{pH}-$ Wert 2,6) erodiert. Die Calciumfreisetzung wurde photometrisch bestimmt (Fluitest CA AllI, Analyticon). Außerdem wurde die Gesamtproteinkonzentration in der Pellikel (je $n=1$ Schmelz- und Dentinprüfkörper pro Proband*in) und verschiedene Speichelparameter wie Fließrate, $\mathrm{pH}$ Wert, Pufferkapazität, Calcium-, Phosphat-, Fluorid- sowie Gesamtprotein- und Albumingehalt analysiert. Die statistische Auswertung erfolgte mittels einfaktorieller ANOVA, t-Tests, multipler linearer Regressionsanalyse und Pearson-Korrelationen $(p<0,05)$.

Es gab keinen signifikanten Unterschied zwischen Frauen und Männern bezüglich der Calciumfreisetzung aus pellikelbedeckten Schmelz- und Dentinprüfkörpern (Calciumfreisetzung in $\mathrm{nmol} / \mathrm{mm}^{2}$ : Frauen: Schmelz

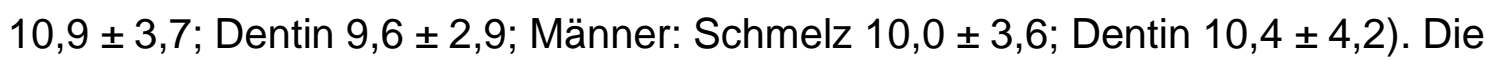
Gesamtproteinkonzentration in der Pellikel zeigte ebenfalls keinen signifikanten Unterschied zwischen den Geschlechtern. Im unstimulierten Speichel waren die Gesamtproteinkonzentration und der $\mathrm{pH}$-Wert bei Frauen signifikant niedriger als bei Männern. Weder die Gesamtproteinkonzentration in der Pellikel noch die analysierten Speichelparameter hatten einen Einfluss auf die durch Säure induzierte Calciumfreisetzung der Probenkörper.

Diese Studie stellte keine geschlechtsspezifischen Unterschiede im Erosionsschutz der Pellikel, trotz signifikanter Unterschiede bezüglich einiger Speichelparameter im unstimulierten Speichel, fest. 


\section{Literaturverzeichnis}

Addy M, Shellis RP (2006): Interaction between attrition, abrasion and erosion in tooth wear. Monogr Oral Sci 20, 17-31

Aguirre A, Mendoza B, Levine MJ, Hatton MN, Douglas WH (1989): In vitro characterization of human salivary lubrication. Arch Oral Biol 34, 675-677

Al-Ashtal A, Johansson A, Omar R, Johansson AK (2017): Dental erosion in groups of Yemeni children and adolescents and the modification of an erosion partial recording system. Int J Paediatr Dent 27, 283-292

Amaechi BT, Higham SM, Edgar WM, Milosevic A (1999): Thickness of acquired salivary pellicle as a determinant of the sites of dental erosion. J Dent Res 78, $1821-1828$

Aoba T, Moreno EC, Hay DI (1984): Inhibition of apatite crystal growth by the amino-terminal segment of human salivary acidic proline-rich proteins. Calcif Tissue Int $\underline{36}, 651-658$

Attin T (2006): Methods for assessment of dental erosion. Monogr Oral Sci 20, $152-172$

Attin T, Becker K, Hannig C, Buchalla W, Hilgers R (2005): Method to detect minimal amounts of calcium dissolved in acidic solutions. Caries Res $\underline{39}$, 432-436

Attin T, Wegehaupt F, Gries D, Wiegand A (2007): The potential of deciduous and permanent bovine enamel as substitute for deciduous and permanent human enamel: erosion-abrasion experiments. J Dent $\underline{35}, 773-777$

Barbour ME, Rees JS (2004): The laboratory assessment of enamel erosion: a review. J Dent 32, 591-602

Barbour ME, Lussi A (2014): Erosion in relation to nutrition and the environment. Monogr Oral Sci $\underline{25}, 143-154$

Bardsley PF, Taylor S, Milosevic A (2004): Epidemiological studies of tooth wear and dental erosion in 14-year-old children in North West England. Part 1: The relationship with water fluoridation and social deprivation. $\mathrm{Br}$ Dent $\mathrm{J}$ 197, 413-416

Bartlett D (2006): Intrinsic causes of erosion. Monogr Oral Sci 20, 119-139

Bartlett D, Ganss C, Lussi A (2008): Basic Erosive Wear Examination (BEWE): a new scoring system for scientific and clinical needs. Clin Oral Investig $\underline{12}$, 65-68

Baumann T, Kozik J, Lussi A, Carvalho T (2016): Erosion protection conferred by whole human saliva, dialysed saliva, and artificial saliva. Sci Rep $\underline{6}, 34760$ 
Baumann T, Bereiter R, Lussi A, Carvalho TS (2017): The effect of different salivary calcium concentrations on the erosion protection conferred by the salivary pellicle. Sci Rep $\underline{7}, 12999$

Bennick A, Cannon M, Madapallimattam G (1979): The nature of the hydroxyapatite-binding site in salivary acidic proline-rich proteins. Biochem J $\underline{183}, 115-126$

Berg ICH, Rutland MW, Arnebrant T (2003): Lubricating properties of the initial salivary pellicle-an AFM study. Biofouling 19, 365-369

Berg ICH, Lindh L, Arnebrant T (2004): Intraoral lubrication of PRP-1, statherin and mucin as studied by AFM. Biofouling 20, 65-70

Bocklandt S, Lin W, Sehl ME, Sánchez FJ, Sinsheimer JS, Horvath S, Vilain E (2011): Epigenetic predictor of age. PLoS One $\underline{6}$, e14821

Bruvo M, Moe D, Kirkeby S, Vorum H, Bardow A (2009): Individual variations in protective effects of experimentally formed salivary pellicles. Caries Res $\underline{43}, 163-170$

Buchgraber B, Kqiku L, Reibnegger G, Städtler P (2013): The weak spots of saliva buffering tests. Coll Antropol $\underline{37}, 999-1001$

Buczkowska-Radlińska J, Łagocka R, Kaczmarek W, Górski M, Nowicka A (2013): Prevalence of dental erosion in adolescent competitive swimmers exposed to gas-chlorinated swimming pool water. Clin Oral Investig 17, 579-583

Buzalaf MAR, Hannas AR, Kato MT (2012): Saliva and dental erosion. J Appl Oral Sci 20 , 493-502

Cabras T, Pisano E, Boi R, Olianas A, Manconi B, Inzitari R, Fanali C, Giardina B, Castagnola M, Messana I (2009): Age-dependent modifications of the human salivary secretory protein complex. J Proteome Res $\underline{8}, 4126-4134$

Carlén A, Nikdel K, Wennerberg A, Holmberg K, Olsson J (2001): Surface characteristics and in vitro biofilm formation on glass ionomer and composite resin. Biomaterials $\underline{22}, 481-487$

Carpenter G, Cotroneo E, Moazzez R, Rojas-Serrano M, Donaldson N, Austin R, Zaidel L, Bartlett D, Proctor G (2014): Composition of enamel pellicle from dental erosion patients. Caries Res $\underline{48}, 361-367$

Cheaib Z, Lussi A (2011): Impact of acquired enamel pellicle modification on initial dental erosion. Caries Res $\underline{45}, 107-112$

Chiappin S, Antonelli G, Gatti R, De Palo EF (2007): Saliva specimen: a new laboratory tool for diagnostic and basic investigation. Clin Chim Acta $\underline{383}$, $30-40$ 
Corrêa MC, Lerco MM, Cunha Mde L, Henry MA (2012): Salivary parameters and teeth erosions in patients with gastroesophageal reflux disease. Arq Gastroenterol $\underline{49}$, 214-218

da Silva Ventura TM, de Paula Silva Cassiano L, de Souza E Silva CM, Taira EA, Leite A de L, Rios D, Buzalaf MAR (2017): The proteomic profile of the acquired enamel pellicle according to its location in the dental arches. Arch Oral Biol $\underline{79}, 20-29$

Dawes C (1974): Rhythms in salivary flow rate and composition. Int J Chronobiol 2, 253-279

Dawes C, Watanabe S, Biglow-Lecomte P, Dibdin GH (1989): Estimation of the velocity of the salivary film at some different locations in the mouth. J Dent Res $\underline{68}, 1479-1482$

Delecrode TR, Siqueira WL, Zaidan FC, Bellini MR, Leite AL, Xiao Y, Rios D, Magalhães AC, Buzalaf MAR (2015a): Exposure to acids changes the proteomic of acquired dentine pellicle. J Dent $\underline{43}, 583-588$

Delecrode TR, Siqueira WL, Zaidan FC, Bellini MR, Moffa EB, Mussi MCM, Xiao Y, Buzalaf MAR (2015b): Identification of acid-resistant proteins in acquired enamel pellicle. J Dent $\underline{43}, 1470-1475$

Dige I, Nilsson H, Kilian M, Nyvad B (2007): In situ identification of streptococci and other bacteria in initial dental biofilm by confocal laser scanning microscopy and fluorescence in situ hybridization. Eur J Oral Sci $\underline{115}, 459-$ 467

Dige I, Raarup MK, Nyengaard JR, Kilian M, Nyvad B (2009): Actinomyces naeslundii in initial dental biofilm formation. Microbiology 155, 2116-2126

Dodds MWJ, Johnson DA, Yeh CK (2005): Health benefits of saliva: a review. J Dent 33, 223-233

Douglas CW (1994): Bacterial-protein interactions in the oral cavity. Adv Dent Res $\underline{8}, 254-262$

Douglas WH, Reeh ES, Ramasubbu N, Raj PA, Bhandary KK, Levine MJ (1991): Statherin: a major boundary lubricant of human saliva. Biochem Biophys Res Commun 180, 91-97

Dugmore CR, Rock WP (2003): The progression of tooth erosion in a cohort of adolescents of mixed ethnicity. Int J Paediatr Dent 13, 295-303

Dugmore CR, Rock WP (2004): The prevalence of tooth erosion in 12-year-old children. Br Dent J $\underline{196}$, 279-282

Edgar WM (1990): Saliva and dental health. Clinical implications of saliva: report of a consensus meeting. Br Dent J $\underline{169}, 96-98$ 
Edgar WM (1992): Saliva: its secretion, composition and functions. Br Dent J $\underline{172}$, 305-312

Falla-Sotelo FO, Rizzutto MA, Tabacniks MH, Added N, Barbosa MDL, Markarian RA, Quinelato A, Mori M, Youssef M (2005): Analysis and discussion of trace elements in teeth of different animal species. Brazilian J Phys $\underline{35}$, $761-762$

Finke M, Parker DM, Jandt KD (2002): Influence of soft drinks on the thickness and morphology of in situ acquired pellicle layer on enamel. J Colloid Interface Sci 251, 263-270

Fleissig Y, Reichenberg E, Redlich M, Zaks B, Deutsch O, Aframian DJ, Palmon A (2010): Comparative proteomic analysis of human oral fluids according to gender and age. Oral Dis $\underline{16}, 831-838$

Ganss C, Klimek J, Schwarz N (2000): A comparative profilometric in vitro study of the susceptibility of polished and natural human enamel and dentine surfaces to erosive demineralization. Arch Oral Biol 45, 897-902

Ganss C, Lussi A, Scharmann I, Weigelt T, Hardt M, Klimek J, Schlueter N (2009): Comparison of calcium analysis, longitudinal microradiography and profilometry for the quantitative assessment of erosion in dentine. Caries $\operatorname{Res} \underline{43}, 422-429$

Ganss C, Lussi A, Schlueter N (2014): The histological features and physical properties of eroded dental hard tissues. Monogr Oral Sci 25, 99-107

Gose M, Krems C, Heuer T, Hoffmann I (2016): Trends in food consumption and nutrient intake in Germany between 2006 and 2012: results of the german national nutrition monitoring (NEMONIT). Br J Nutr 115, 1498-1507

Gregoire S, Xiao J, Silva BB, Gonzalez I, Agidi PS, Klein MI, Ambatipudi KS, Rosalen PL, Bauserman R, Waugh RE, Koo H (2011): Role of glucosyltransferase $\mathrm{b}$ in interactions of candida albicans with streptococcus mutans and with an experimental pellicle on hydroxyapatite surfaces. Appl Environ Microbiol 77, 6357-6367

Hannig C, Hannig M (2009): The oral cavity-a key system to understand substratum-dependent bioadhesion on solid surfaces in man. Clin Oral Investig 13, 123-139

Hannig C, Attin T, Hannig M, Henze E, Brinkmann K, Zech R (2004): Immobilisation and activity of human alpha-amylase in the acquired enamel pellicle. Arch Oral Biol $\underline{49}$, 469-475

Hannig C, Hannig M, Attin T (2005a): Enzymes in the acquired enamel pellicle. Eur J Oral Sci $\underline{113}, 2-13$ 
Hannig C, Hamkens A, Becker K, Attin R, Attin T (2005b): Erosive effects of different acids on bovine enamel: release of calcium and phosphate in vitro. Arch Oral Biol $\underline{50}, 541-552$

Hannig C, Becker K, Häusler N, Hoth-Hannig W, Attin T, Hannig M (2007): Protective effect of the in situ pellicle on dentin erosion-an ex vivo pilot study. Arch Oral Biol $\underline{52}, 444-449$

Hannig C, Becker K, Yankeu-Ngalene VE, Attin T (2008): Applicability of common methods for short time erosion analysis in vitro. Oral Health Prev Dent $\underline{6}$, 239-248

Hannig C, Berndt D, Hoth-Hannig W, Hannig M (2009): The effect of acidic beverages on the ultrastructure of the acquired pellicle-an in situ study. Arch Oral Biol $\underline{54}, 518-526$

Hannig C, Wagenschwanz C, Pötschke S, Kümmerer K, Kensche A, HothHannig W, Hannig M (2012): Effect of safflower oil on the protective properties of the in situ formed salivary pellicle. Caries Res $\underline{46}, 496-506$

Hannig M (1997): Transmission electron microscopic study of in vivo pellicle formation on dental restorative materials. Eur J Oral Sci 105, 422-433

Hannig M (1999a): Transmission electron microscopy of early plaque formation on dental materials in vivo. Eur J Oral Sci $107,55-64$

Hannig M (1999b): Ultrastructural investigation of pellicle morphogenesis at two different intraoral sites during a 24 -h period. Clin Oral Investig $\underline{3}, 88-95$

Hannig M, Balz M (1999): Influence of in vivo formed salivary pellicle on enamel erosion. Caries Res $\underline{33}, 372-379$

Hannig M, Balz M (2001): Protective properties of salivary pellicles from two different intraoral sites on enamel erosion. Caries Res $\underline{35}, 142-148$

Hannig M, Joiner A (2006): The structure, function and properties of the acquired pellicle. Monogr Oral Sci $\underline{19}$, 29-64

Hannig M, Hannig C (2014): The pellicle and erosion. Monogr Oral Sci $\underline{25}$, 206214

Hannig M, Hess NJ, Hoth-Hannig W, De Vrese M (2003): Influence of salivary pellicle formation time on enamel demineralization-an in situ pilot study. Clin Oral Investig $\underline{7}, 158-161$

Hannig M, Döbert A, Stigler R, Müller U, Prokhorova SA (2004a): Initial salivary pellicle formation on solid substrates studied by AFM. J. Nanosci Nanotech $\underline{4}, 1-7$ 
Hannig M, Fiebiger M, Güntzer M, Döbert A, Zimehl R, Nekrashevych Y (2004b): Protective effect of the in situ formed short-term salivary pellicle. Arch Oral Biol $\underline{49}, 903-910$

Hara AT, Zero DT (2008): Analysis of the erosive potential of calcium-containing acidic beverages. Eur J Oral Sci 116, 60-65

Hara AT, Zero DT (2014): The potential of saliva in protecting against dental erosion. Monogr Oral Sci $\underline{25}, 197-205$

Hara AT, Ando M, González-Cabezas C, Cury JA, Serra MC, Zero DT (2006): Protective effect of the dental pellicle against erosive challenges in situ. $J$ Dent Res $\underline{85}, 612-616$

Hasselkvist A, Johansson A, Johansson AK (2010): Dental erosion and soft drink consumption in swedish children and adolescents and the development of a simplified erosion partial recording system. Swed Dent J $\underline{34}, 187-195$

Hay DI (1973): The interaction of human parotid salivary proteins with hydroxyapatite. Arch Oral Biol $\underline{18}$, 1517-1529

Hay DI, Schluckebier SK, Moreno EC (1982): Equilibrium dialysis and ultrafiltration studies of calcium and phosphate binding by human salivary proteins. Implications for salivary supersaturation with respect to calcium phosphate salts. Calcif Tissue Int $\underline{34}, 531-538$

Hellwig E, Lussi A (2014): Oral hygiene products, medications and drugs - hidden aetiological factors for dental erosion. Monogr Oral Sci $\underline{25}$, 155-162

Herkströter FM, Witjes M, Arends J (1991): Demineralization of human dentine compared with enamel in a pH-cycling apparatus with a constant composition during de- and remineralization periods. Caries Res $\underline{25}$, 317322

Hermont AP, Oliveira PAD, Martins CC, Paiva SM, Pordeus IA, Auad SM (2014): Tooth erosion and eating disorders: a systematic review and metaanalysis. PLoS One $\underline{9}$, e111123

Humphrey SP, Williamson RT (2001): A review of saliva: normal composition, flow, and function. J Prosthet Dent $\underline{85}, 162-169$

Huysmans MCDNJM, Chew HP, Ellwood RP (2011): Clinical studies of dental erosion and erosive wear. Caries Res 45 Suppl 1, 60-68

Jaeggi T, Lussi A (1999): Toothbrush abrasion of erosively altered enamel after intraoral exposure to saliva: an in situ study. Caries Res $\underline{33}, 455-461$

Jaeggi T, Lussi A (2014): Prevalence, incidence and distribution of erosion. Monogr Oral Sci $\underline{25}, 55-73$ 
Jager DHJ, Vieira AM, Ligtenberg AJM, Bronkhorst E, Huysmans MCDNJM, Vissink A (2011): Effect of salivary factors on the susceptibility of hydroxyapatite to early erosion. Caries Res $\underline{45}, 532-537$

Järvinen VK, Rytömaa II, Heinonen OP (1991): Risk factors in dental erosion. J Dent Res $\underline{70}, 942-947$

Jensdottir T, Buchwald C, Nauntofte B, Hansen HS, Bardow A (2013): Saliva in relation to dental erosion before and after radiotherapy. Acta Odontol Scand $\underline{71}, 1008-1013$

Jensen JL, Lamkin MS, Oppenheim FG (1992): Adsorption of human salivary proteins to hydroxyapatite: a comparison between whole saliva and glandular salivary secretions. J Dent Res $\underline{71}, 1569-1576$

Johansson AK, Lingström P, Birkhed D (2002): Comparison of factors potentially related to the occurrence of dental erosion in high- and low-erosion groups. Eur J Oral Sci 110, 204-211

Johansson AK, Norring C, Unell L, Johansson A (2012): Eating disorders and oral health: a matched case-control study. Eur J Oral Sci $\underline{120}$, 61-68

Joiner A, Schwarz A, Philpotts CJ, Cox TF, Huber K, Hannig M (2008): The protective nature of pellicle towards toothpaste abrasion on enamel and dentine. J Dent 36, 360-368

Kinney JH, Balooch M, Haupt DL, Marshall SJ, Marshall GW (1995): Mineral distribution and dimensional changes in human dentin during demineralization. J Dent Res $\underline{74}, 1179-1184$

Lamkin MS, Arancillo AA, Oppenheim EG (1996): Temporal and compositional characteristics of salivary protein adsorption to hydroxyapatite. J Dent Res $\underline{75}, 803-808$

Larsen MJ, Pearce EIF (2003): Saturation of human saliva with respect to calcium salts. Arch Oral Biol $\underline{48}, 317-322$

Lee YH, Zimmerman JN, Custodio W, Xiao Y, Basiri T, Hatibovic-Kofman S, Siqueira WL (2013): Proteomic evaluation of acquired enamel pellicle during in vivo formation. PLoS One $\underline{8}$, e67919

Lendenmann U, Grogan J, Oppenheim FG (2000): Saliva and dental pellicle - a review. Adv Dent Res 14, 22-28

Li J, Helmerhorst EJ, Troxler RF, Oppenheim FG (2004a): Identification of in vivo pellicle constituents by analysis of serum immune responses. J Dent Res 83, 60-64

Li J, Helmerhorst EJ, Yao Y, Nunn ME, Troxler RF, Oppenheim FG (2004b): Statherin is an in vivo pellicle constituent: identification and immunoquantification. Arch Oral Biol $\underline{49}$, 379-385 
Li-Hui W, Chuan-Quan L, Long Y, Ru-Liu L, Long-Hui C, Wei-Wen C (2016): Gender differences in the saliva of young healthy subjects before and after citric acid stimulation. Clin Chim Acta $\underline{460}, 142-145$

Lin WT, Kitasako Y, Nakashima S, Tagami J (2017): A comparative study of the susceptibility of cut and uncut enamel to erosive demineralization. Dent Mater $\underline{36}, 48-53$

Liu J, Duan Y (2012): Saliva: a potential media for disease diagnostics and monitoring. Oral Oncol $\underline{48}, 569-577$

Lussi A, Carvalho TS (2014): Erosive tooth wear: a multifactorial condition of growing concern and increasing knowledge. Monogr Oral Sci 25, 1-15

Lussi A, Hellwig E (2014): Risk assessment and causal preventive measures. Monogr Oral Sci $\underline{25}, 220-229$

Lussi A, Jaeggi T, Zero D (2004): The role of diet in the aetiology of dental erosion. Caries Res 38 Suppl 1, 34-44

Lussi A, Hellwig E, Zero D, Jaeggi T (2006): Erosive tooth wear: diagnosis, risk factors and prevention. Am J Dent $\underline{19}, 319-325$

Lussi A, Schlueter N, Rakhmatullina E, Ganss C (2011): Dental erosion - an overview with emphasis on chemical and histopathological aspects. Caries Res $\underline{45}, 2-12$

Maharani DA, Zhang S, Gao SS, Chu C-H, Rahardjo A (2019): Dental caries and the erosive tooth wear status of 12-year-old children in Jakarta, Indonesia. Int J Environ Res Public Health 16, 2994

Meurman JH, Frank RM (1991): Scanning electron microscopic study of the effect of salivary pellicle on enamel erosion. Caries Res $\underline{25}, 1-6$

Meurman JH, ten Cate JM (1996): Pathogenesis and modifying factors of dental erosion. Eur J Oral Sci 104, 199-206

Meurman JH, Toskala J, Nuutinen P, Klemetti E (1994): Oral and dental manifestations in gastroesophageal reflux disease. Oral Surg Oral Med Oral Pathol $\underline{78}, 583-589$

Milosevic A, Young PJ, Lennon MA (1994): The prevalence of tooth wear in 14year-old school children in Liverpool. Community Dent Health 11, 83-86

Moazzez R, Bartlett D (2014): Intrinsic causes of erosion. Monogr Oral Sci $\underline{25}$, 180-196

Moazzez R, Bartlett D, Anggiansah A (2004): Dental erosion, gastrooesophageal reflux disease and saliva: How are they related? J Dent $\underline{32}$, 489-494 
Moreno EC, Varughese K, Hay DI (1979): Effect of human salivary proteins on the precipitation kinetics of calcium phosphate. Calcif Tissue Int 28, 7-16

Müller R, Hiller KA, Schmalz G, Ruhl S (2006): Chemiluminescence-based detection and comparison of protein amounts adsorbed on differently modified silica surfaces. Anal Biochem $\underline{359}, 194-202$

Murr A, Pink C, Hammer E, Michalik S, Dhople VM, Holtfreter B, Völker U, Kocher T, Gesell Salazar M (2017): Cross-sectional association of salivary proteins with age, sex, body mass index, smoking and education. $J$ Proteome Res $\underline{16}$, 2273-2281

Mutahar M, O'Toole S, Carpenter G, Bartlett D, Andiappan M, Moazzez R (2017): Reduced statherin in acquired enamel pellicle on eroded teeth compared to healthy teeth in the same subjects: An in-vivo study. PLoS One 12, e0183660

Nekrashevych Y, Stösser L (2003): Protective influence of experimentally formed salivary pellicle on enamel erosion. An in vitro study. Caries Res $\underline{37}, 225-$ 231

Nyvad B, Fejerskov O (1987): Transmission electron microscopy of early microbial colonization of human enamel and root surfaces in vivo. Scand J Dent Res 95, 297-307

Prodan A, Brand HS, Ligtenberg AJM, Imangaliyev S, Tsivtsivadze E, van der Weijden F, Crielaard W, Keijser BJF, Veerman ECI (2015): Interindividual variation, correlations, and sex-related differences in the salivary biochemistry of young healthy adults. Eur J Oral Sci 123, 149-157

Reich M, Hannig C, Al-Ahmad A, Bolek R, Kümmerer K (2012): A comprehensive method for determination of fatty acids in the initial oral biofilm (pellicle). $J$ Lipid Res 53, 2226-2230

Rosan B, Lamont RJ (2000): Dental plaque formation. Microbes Infect 2, 15991607

Rytömaa I, Järvinen V, Kanerva R, Heinonen OP (1998): Bulimia and tooth erosion. Acta Odontol Scand $\underline{56}, 36-40$

Salas MMS, Vargas-Ferreira F, Ardenghi TM, Peres KG, Huysmans MCDNJM, Demarco FF (2017): Prevalence and associated factors of tooth erosion in 8 -12-year-old brazilian schoolchildren. J Clin Pediatr Dent 41, 343-350

Schlueter N, Luka B (2018): Erosive tooth wear - a review on global prevalence and on its prevalence in risk groups. Br Dent $\mathrm{J} \underline{224}, 364-370$

Schlueter N, Ganss C, Sanctis SD, Klimek J (2005): Evaluation of a profilometrical method for monitoring erosive tooth wear. Eur J Oral Sci $\underline{113}, 505-511$ 
Schlueter N, Hardt M, Klimek J, Ganss C (2010): Influence of the digestive enzymes trypsin and pepsin in vitro on the progression of erosion in dentine. Arch Oral Biol 55, 294-299

Schlueter N, Hara A, Shellis RP, Ganss C (2011): Methods for the measurement and characterization of erosion in enamel and dentine. Caries Res $\underline{45}, 13-$ 23

Schlueter N, Amaechi BT, Bartlett D, Buzalaf MAR, Carvalho TS, Ganss C, Hara AT, Huysmans MCDNJM, Lussi A, Moazzez R, et al. (2020): Terminology of erosive tooth wear: consensus report of a workshop organized by the ORCA and the cariology research group of the IADR. Caries Res $\underline{54}, 2-6$

Siqueira WL, Zhang W, Helmerhorst EJ, Gygi SP, Oppenheim FG (2007): Identification of protein components in in vivo human acquired enamel pellicle using LC-ESI-MS/MS. J Proteome Res $\underline{6}$, 2152-2160

Siqueira WL, Margolis HC, Helmerhorst EJ, Mendes FM, Oppenheim FG (2010): Evidence of intact histatins in the in vivo acquired enamel pellicle. J Dent Res $\underline{89}$, 626-630

Siqueira WL, Bakkal M, Xiao Y, Sutton JN, Mendes FM (2012): Quantitative proteomic analysis of the effect of fluoride on the acquired enamel pellicle. PLoS One 7: e42204

Skjørland KK, Rykke M, Sønju T (1995): Rate of pellicle formation in vivo. Acta Odontol Scand $\underline{53}, 358-362$

Smith BG, Robb ND (1989): Dental erosion in patients with chronic alcoholism. J Dent $\underline{17}, 219-221$

Smith HG, Bauer PJ (1979): Light-induced permeability changes in sonicated bovine disks: Arsenazo III and flow system measurements. Biochemistry $\underline{18}, 5067-5073$

Sönju T, Christensen TB, Kornstad L, Rölla G (1974): Electron microscopy, carbohydrate analyses and biological activities of the proteins adsorbed in two hours to tooth surfaces in vivo. Caries Res $\underline{8}, 113-122$

Srivastava A, Wang J, Zhou H, Melvin JE, Wong DT (2008): Age and gender related differences in human parotid gland gene expression. Arch Oral Biol $\underline{53}, 1058-1070$

Tabak LA (1995): In defense of the oral cavity: structure, biosynthesis, and function of salivary mucins. Annu Rev Physiol $\underline{57}$, 547-564

Tabak LA, Levine MJ, Mandel ID, Ellison SA (1982): Role of salivary mucins in the protection of the oral cavity. J Oral Pathol $\underline{11}, 1-17$

Tenovuo J (1997): Salivary parameters of relevance for assessing caries activity in individuals and populations. Community Dent Oral Epidemiol 25, 82-86 
Tenovuo J (1998): Antimicrobial function of human saliva-how important is it for oral health? Acta Odontol Scand $\underline{56}, 250-256$

Thomas MS, Vivekananda Pai AR, Yadav A (2015): Medication-related dental erosion: a review. Compend Contin Educ Dent 36, 662-666

Trudeau DL, Freier EF (1967): Determination of calcium in urine and serum by atomic absorption spectrophotometry (AAS). Clin Chem $\underline{13}, 101-114$

Tschammler C, Müller-Pflanz C, Attin T, Müller J, Wiegand A (2016): Prevalence and risk factors of erosive tooth wear in 3-6 year old German kindergarten children - a comparison between 2004/05 and 2014/15. J Dent 2, 45-49

Turssi CP, Messias DF, Corona SM, Serra MC (2010): Viability of using enamel and dentin from bovine origin as a substitute for human counterparts in an intraoral erosion model. Brazilian Dent J 21, 332-336

Uhlen MM, Tveit AB, Stenhagen KR, Mulic A (2014): Self-induced vomiting and dental erosion-a clinical study. BMC Oral Health $\underline{14}, 92$

Uhlen MM, Mulic A, Holme B, Tveit AB, Stenhagen KR (2016a): The susceptibility to dental erosion differs among individuals. Caries Res $\underline{50}, 117-123$

Uhlen MM, Stenhagen KR, Dizak PM, Holme B, Mulic A, Tveit AB, Vieira AR (2016b): Genetic variation may explain why females are less susceptible to dental erosion. Eur J Oral Sci $\underline{124}$, 426-432

Vacca Smith AM, Bowen WH (2000): In situ studies of pellicle formation on hydroxyapatite discs. Arch Oral Biol $\underline{45}, 277-291$

van Nieuw Amerongen, Bolscher JGM, Veerman ECI (2004): Salivary proteins: protective and diagnostic value in cariology? Caries Res $\underline{38}, 247-253$

van Rijkom HM, Truin GJ, Frencken JEFM, König KG, van 't Hof MA, Bronkhorst EM, Roeters FJM (2002): Prevalence, distribution and background variables of smooth-bordered tooth wear in teenagers in the Hague, the Netherlands. Caries Res $\underline{36}, 147-154$

Veerman EC, van den Keybus PA, Vissink A, van Nieuw Amerongen A (1996): Human glandular salivas: their separate collection and analysis. Eur J Oral Sci $104,346-352$

Vitkov L, Hannig M, Nekrashevych Y, Krautgartner WD (2004): Supramolecular pellicle precursors. Eur J Oral Sci 112, 320-325

Voronets J, Lussi A (2010): Thickness of softened human enamel removed by toothbrush abrasion: an in vitro study. Clin Oral Investig 14, 251-256

Voronets J, Jaeggi T, Buergin W, Lussi A (2008): Controlled toothbrush abrasion of softened human enamel. Caries Res $\underline{42}, 286-290$ 
Weber MT, Hannig M, Pötschke S, Höhne F, Hannig C (2015): Application of plant extracts for the prevention of dental erosion: an in situ/in vitro study. Caries Res $\underline{49}$, 477-487

Wegehaupt F, Gries D, Wiegand A, Attin T (2008): Is bovine dentine an appropriate substitute for human dentine in erosion/abrasion tests? J Oral Rehabil 35, 390-394

West NX, Hughes JA, Addy M (2001): The effect of pH on the erosion of dentine and enamel by dietary acids in vitro. J Oral Rehabil 28, 860-864

Wetton S, Hughes J, West N, Addy M (2006): Exposure time of enamel and dentine to saliva for protection against erosion: a study in vitro. Caries Res $\underline{40}, 213-217$

Wetton S, Hughes J, Newcombe RG, Addy M (2007): The effect of saliva derived from different individuals on the erosion of enamel and dentine. A study in vitro. Caries Res $\underline{41}, 423-426$

Wiegand A, Attin T (2007): Occupational dental erosion from exposure to acids a review. Occup Med 57, 169-176

Wiegand A, Bliggenstorfer S, Magalhães AC, Sener B, Attin T (2008a): Impact of the in situ formed salivary pellicle on enamel and dentine erosion induced by different acids. Acta Odontol Scand $\underline{66}, 225-230$

Wiegand A, Meier W, Sutter E, Magalhães AC, Becker K, Roos M, Attin T (2008b): Protective effect of different tetrafluorides on erosion of pelliclefree and pellicle-covered enamel and dentine. Caries Res $\underline{42}, 247-254$

Wiktorsson AM, Zimmerman M, Angmar-Månsson B (1997): Erosive tooth wear: prevalence and severity in swedish winetasters. Eur J Oral Sci $\underline{105}, 544$ 550

Willis JB (1961): Determination of calcium and magnesium in urine by atomic absorption spectroscopy. Anal Chem $\underline{33}, 556-559$

Xiao X, Liu Y, Guo Z, Liu X, Sun H, Li Q, Sun W (2017): Comparative proteomic analysis of the influence of gender and acid stimulation on normal human saliva using LC/MS/MS. Proteomics Clin Appl 11, 1600142

Young A, Rykke M, Rölla G (1999): Quantitative and qualitative analyses of human salivary micelle-like globules. Acta Odontol Scand 57, 105-110

Zahradnik RT, Propas D, Moreno EC (1977): In vitro enamel demineralization by Streptococcus mutans in the presence of salivary pellicles. J Dent Res $\underline{56}$, 1107-1110

Zero DT (1996): Etiology of dental erosion - extrinsic factors. Eur J Oral Sci 104, 162-177 
Zero DT, Hara AT, Kelly SA, González-Cabezas C, Eckert GJ, Barlow AP, Mason SC (2006): Evaluation of a desensitizing test dentifrice using an in situ erosion remineralization model. J Clin Dent $\underline{17}, 112-116$

Zwier N, Huysmans MCDNJM, Jager DHJ, Ruben J, Bronkhorst EM, Truin GJ (2013): Saliva parameters and erosive wear in adolescents. Caries Res $\underline{47}, 548-552$ 


\section{Danksagung}

Mein besonderer Dank gilt Frau Prof. Wiegand für die Anregung zur Arbeit und Betreuung als Doktormutter sowie Herrn Prof. Doenecke als Zweitbetreuer. Des Weiteren danke ich Herrn Dr. Dr. Kanzow für die Betreuung der Doktorarbeit.

Weiterhin danke ich den labortechnischen Mitarbeiterinnen der Poliklinik für Präventive Zahnmedizin, Parodontologie und Kariologie im Zentrum für Zahn-, Mund- und Kieferheilkunde Göttingen, die mich während der Experimente mit Rat und Tat unterstützt haben, ganz besonders Frau M. Hoch und S. Barke.

Herzlichen Dank an alle Proband*innen, die zur Durchführung der vorliegenden Studie beigetragen haben, der dgpzm die das Forschungsvorhaben aus dem dgpzm CP GABA Wissenschaftsfonds 2017 unterstützt hat und der Firma Gebr. Brasseler, Lemgo, für die kostenlose Anfertigung der diamantierten Trepanbohrer. 


\section{Lebenslauf}

